ISSN: 0213-2079 - ISSN electrónico: 2386-3889

DOI: https://doi.org/10.14201/shhmo2019411153188

\title{
UN NUEVO ESCENARIO DE LA GUERRA CON FRANCIA. LA INTERVENCIÓN ESPAÑOLA EN LA FRONDA (1648-1653)
}

\section{A New Theatre of the War with France. The Spanish intervention in the Fronde (1648-1653)}

\author{
Lourdes AMIGO VÁZQUEZ ${ }^{1}$ \\ Universidad de Valladolid \\ Correo-e: lourdesamigo@gmail.com
}

RESUMEN: Cientos de páginas se han escrito sobre la Fronda, siempre con la misma constante: una escasa atención a la Monarquía Hispánica. Pero en el marco de la guerra por la hegemonía europea (1635-1659), Felipe IV no podía desaprovechar la gran ocasión que se presentaba para intervenir en los conflictos internos de Francia y, de esta forma, restar fuerzas al enemigo, al igual que este hacía en Cataluña y Portugal (y antes en Italia). Con un análisis global de la participación española en las revueltas, a través, principalmente, de la rica documentación conservada en el Archivo General de Simancas, se trata de dar el primer paso para llenar un importante vacío historiográfico que existe todavía a ambos lados de los Pirineos. De esta forma se comprobará hasta qué punto, a la altura de los años 1648-1653, no todo estaba ya decidido en la Guerra Franco-Española y cómo la Fronda no fue un «asunto» exclusivamente francés.

Palabras clave: Siglo XVII; Monarquía Hispánica; Francia; Fronda; política internacional; Felipe IV; Louis XIV; Louis II de Bourbon-Condé.

1. Este trabajo ha sido realizado en el marco del proyecto Hispanofilia III: la influencia ibérica en su contexto político, siglos XVI-XX, Código HAR2014-52414-C2-1-P, del MINECO.

Ediciones Universidad de Salamanca / @®@@ Stud. his., H. ${ }^{a}$ mod., 41, n. 1 (2019), pp. 153-188 
LOURDES AMIGO VÁZQUEZ

UN NUEVO ESCENARIO DE LA GUERRA CON FRANCIA.

LA INTERVENCIÓN ESPAÑOLA EN LA FRONDA (1648-1653)

\begin{abstract}
Thousands of pages have been dedicated to the Fronde, all of them based upon the same underlying assumption: little or no attention has been paid to the involvement of the Spanish Monarchy. Yet given the context of a pan-European struggle for hegemony (1635-1659), Philip IV could hardly fail to take advantage of this singularly-favourable opportunity to intervene in the internal conflicts of France and so weaken his principal enemy, in much the same way as Paris had become involved in Catalonia and Portugal (and, previously, in Italy.) This thorough but detailed analysis of Spanish involvement in these quintessentially 'French' revolts is principally based upon the rich documentation held in the Archivo General de Simancas, and so constitutes a first step towards correcting a historiographical oversight that still prevails on both sides of the Pyrenees. It will attempt to set out a provisional interpretation of the extent to which the outcome of the Franco-Spanish war had yet to be resolved in the years 1648-1653 and how the Fronde was not an exclusively French affair.
\end{abstract}

Keywords: Seventeenth-century; Spanish Monarchy; France; Fronde; International politics; Philip IV; Louis XIV; Louis II de Bourbon-Condé.

El 2 de julio de 1652 tuvo lugar, inscrita en la sublevación de la Fronda, la batalla del faubourg de Saint Antoine, bajo los muros de París, entre los ejércitos del mariscal Turenne y del Príncipe de Condé. Gracias a la Grande Mademoiselle, la hija del duque de Orleans, que logró abrir la puerta de Saint Antoine y ordenó disparar el cañón de la Bastille, las tropas rebeldes de Louis II de Bourbon, inferiores en número, consiguieron salvarse. Estas pasaron después por medio de la ciudad. Como relata al conde de Fuensaldaña uno de los protagonistas, el soldado Alberto Quenos de Moraes, «es de notar que desde la Liga no se han visto en el Puente Nuevo banderas con la cruz de Borgoña y artillería de su majestad $»^{2}$. Una presencia que tampoco fue inadvertida por los habitantes de París, entre ellos la propia Grande Mademoiselle ${ }^{3}$. No en vano, parte importante de las huestes de Condé estaban formadas por soldados de Felipe IV, del ejército de Flandes ${ }^{4}$.

2. Archivo General de Simancas [en adelante AGS], Estado, leg. 2078, doc. 175, Alberto Quenos de Moraes a Fuensaldaña, 6-VII-1652.

3. PERNOT, M.: La Fronde. 1648-1653. París, 1994, pp. 303-304.

4. De los Países Bajos españoles, en febrero de 1652, el duque de Nemours había salido, junto con las tropas del Príncipe que allí se encontraban (unos 1.500 soldados), con 6.000 hombres dados por el conde de Fuensaldaña, en virtud del tratado firmado con Felipe IV. AGS, Estado, leg. 2078, doc. 13, Junta de Estado, 17-II-1652; Ibid., doc. 48, Fuensaldaña a Felipe IV, 6-II-1652.

Ediciones Universidad de Salamanca / @®@@ Stud. his., H. ${ }^{a}$ mod., 41, n. 1 (2019), pp. 153-188 
LOURDES AMIGO VÁZQUEZ

UN NUEVO ESCENARIO DE LA GUERRA CON FRANCIA.

LA INTERVENCIÓN ESPAÑOLA EN LA FRONDA (1648-1653)

La situación era distinta a la de 1590, cuando las tropas españolas, comandadas por Alejandro de Farnesio, entraron en París, en ayuda de la Liga Católica 5 . No obstante, se pueden establecer algunos paralelismos. Felipe IV, al igual que su abuelo, estaba interviniendo en los asuntos internos de Francia. Es más, después de la Liga, el apoyo a la Fronda fue la mayor implicación española en la política francesa durante toda la Edad Moderna. A finales del Quinientos, la Monarquía Hispánica buscaba asentar su predominio en Europa, ahora, unas décadas más tarde, trataba de no perderlo definitivamente.

Cientos de páginas se han escrito sobre los tumultos en Francia que precedieron al triunfo del Absolutismo, por historiadores franceses, pero también anglosajones ${ }^{6}$. Sin embargo, en sus trabajos nos encontramos con una constante, que también

5. Vid. VÁZQUEZ DE PRADA, V.: Felipe II y Francia (1559-1598). Política, Religión y Razón de Estado. Pamplona, 2004; RUIZ IBÁNEZ, J. J.: Laberintos de hegemonía. La presencia militar de la Monarquía Hispánica en Francia a finales del siglo XVI. Valladolid, 2012.

6. Desde el siglo XIX se trata de uno de los temas estrella de la historia de Francia. El XX fue, sin duda, el siglo de la Fronda, con uno de sus momentos culminantes entre 1950 y 1980, al calor de las controversias ideológicas impulsadas por los historiadores marxistas y sus detractores; se publicaron, entonces, dos libros clásicos: KOSSMANN, E. H.: La Fronde. Leyde, 1954 y MOOTE, A. L.: The Revolt of the judges: the Parlement of Paris and the Fronde, 1643-1652. Princeton, 1971. A partir de la década de los 80, con el retorno a la Historia Política, tuvo lugar una renovación de los estudios de la Fronda; destacan el número monográfico en la revista XVIIe siècle, 145, 4, 1984, y DUCHÊNE, R. y RONZEAUD, P. (dirs.): La Fronde en questions. Aix-en-Provence, 1989. De finales de la centuria son las tres síntesis más recientes: MÉTHIVIER, H.: La Fronde. París, 1984; PERNOT, M.: La Fronde...; RANUM, O. A.: La Fronde. París, 1995. El tema sigue gozando de gran dinamismo en la actualidad: VERGNES, S.: Les frondeuses. Une révolte au féminin (1643-1661). Seyssel, 2013, en consonancia con el desarrollo de los estudios de género, y CONSTANT, J.-M.: C'était la Fronde. París, 2016, quien, estrechamente influenciado por la Nueva Historia Política, plantea una relectura de las revueltas, a través de las ideas y acciones de sus principales protagonistas. No faltan tampoco los estudios sobre la Fronda en Burdeos, si bien, todavía, en los análisis generales no se le presta la suficiente atención, ya que sigue primando el punto de vista parisino: BERCÉ, Y.-M.: Histoire des croquants, étude des soulèvements populaires au XVIIe siècle dans le Sud-Onest de la France. Ginebra, 1974, 2 vols.; JOUHAUD, C.: «Geoffroy Gay: une lecture de la Fronde Bordelaise», Annales du Midi, 91, 143, 1979, pp. 273-295; BIRNSTIEL, E.: Die Fronde in Bordeaux, 1648-1654. Francfort-sur-le-Main, 1985; BLANQUIE, C.: Une vie de frondeur, le chevalier de Thodias (1616-1672). Coutras, 2001. Dado su carácter novedoso y «revolucionario», ha despertado un gran interés l'Ormée, también por parte de la historiografía anglosajona, por la posible influencia en ella de la primera revolución inglesa: WESTRICH, S.A.: The Ormée of Bordeaux: a revolution during the Fronde. Baltimore, 1972; KOTTING, H.: Die Ormée, 16511653. Münster, 1983. En los últimos años, destacan los trabajos de LE MAO, C.: Parlement et Parlementaires. Bordeaux au Grand Siècle. Seyssel, 2007 y SERVANTON, M.: Factions et robes ronges: parlements et politique provinciale de Richelieu à la Fronde (1624-1654), tesis doctoral inédita, Université Bourdeaux Montaigne, 2017, que ponen el acento en el papel del Parlamento de Burdeos, antes minusvalorado.

Ediciones Universidad de Salamanca / @®@@ Stud. his., H. ${ }^{a}$ mod., 41, n. 1 (2019), pp. 153-188 
LOURDES AMIGO VÁZQUEZ

UN NUEVO ESCENARIO DE LA GUERRA CON FRANCIA.

LA INTERVENCIÓN ESPAÑOLA EN LA FRONDA (1648-1653)

sucede en los dedicados a sus principales protagonistas, como Turenne o Condép: la participación española, mencionada de forma tangencial e inconexa, despierta poco interés. Es decir, la Monarquía Hispánica figura como un actor muy secundario ${ }^{8}$. Se tiende a insistir, además, en una cuestión de fondo: Felipe IV, que trató de sacar provecho de tales disturbios, nunca cumplió con los frondistas y su respaldo fue, por ende, muy inferior a lo pactado. Hasta la fecha, tampoco la historiografía española o de corte hispanista ha prestado suficiente atención al tema9

La participación extranjera en la Fronda no se limitó a la española, como han puesto de manifiesto estudios centrados en la suiza ${ }^{10} \mathrm{y}$, particularmente, en la inglesa en Burdeos ${ }^{11}$. Pero, sin lugar a dudas, el papel de la Monarquía Católica, la gran enemiga de Francia y con la que estaba en liza la hegemonía continental, fue el más trascendente. He aquí el objeto de este artículo: presentar un análisis global de dicha intervención, para concretar sus hechos, personajes y características principales, con especial hincapié en la perspectiva española, a través de la rica documentación conservada en la sección de Estado, del Archivo General de Simancas. Se trata del primer paso, para llenar un importante vacío historiográfico que existe todavía a ambos lados de los Pirineos. De esta forma se comprobará hasta qué punto, a la altura de

7. BÉRENGER, J.: Turenne. París, 1987; AUMALE, H. d'Orleans, duque de: Histoire des princes de Condé aux XVe et XVIIe siècles. París, 1892, 1896, vols. 6 y 7; PUJO, B.: Le Grand Condé. París, 1995; BÉGUIN, K.: Les princes de Condé. Rebelles, courtisans et mécènes dans la France du Grand Siècle. Seyssel, 1999; BERTIÈRE, S.: Condé, le héros fourvoyé. París, 2011.

8. Como excepciones podemos citar: THIÉRY, H: «À la découverte d'un acteur de la Fronde à Bordeaux: la mission du baron de Vatteville (1649-1653)», Annales du Midi, 265, 2009, pp. 37-56, y SÉRÉ, D.: La Paix des Pyrénées. Vingt-quatre ans de négociations entre la France et l'Espagne (1635-1659). París, 2007, que, aunque no se centra en la Fronda, ofrece interesantes datos sobre el papel en la misma de la Monarquía Católica.

9. Cabe señalar, como excepciones, las aportaciones de MAFFI, D.: En defensa del Imperio. Los ejércitos de Felipe IV y la guerra por la begemonía europea (1635-1659). Madrid, 2014; BENAVIDES, J. I., Milicia y diplomacia en el reinado de Felipe IV. El marqués de Caracena. Astorga, 2012; BORREGO, M.: «España en las mazarinadas (1648-1652), una aproximación», en GARCÍA LÓPEZ, J. y BOADAS, S. (eds.), Las relaciones de sucesos en los cambios políticos $y$ sociales de la Europa Moderna. Bellaterra, 2015 y USUNÁRIZ GARAYOA, J.: «'Las grandes novedades que ha habido en el reino de Francia'. La Fronda vista desde España», en RONCERO LÓPEZ, V. y ESCUDERO BAZÁN, J. M. (eds.): «Doctos libros juntos». Homenaje al profesor Ignacio Arellano Ayuso. Madrid, 2018, pp. 493-508.

10. BERCÉ, Y.-M.: «Le rôle des Suisses pendant la Fronde: maîtres ou serviteurs?», Cinq siècles de relations franco-suisses. Neuchâtel, 1984, pp. 73-87.

11. SERPELL, D. R.: The condition of Protestantism in France and its influence on the relations of France and England 1650-1654. Toulouse y París, 1934; KNACHEL, P. A.: England and the Fronde. The Impact of the English Civil War and Revolution on France. Ithaca, New York, 1967; GIRY-DELOISON, C.: «Le rôle de l'Anglaterre dans les événements de la Fronde bordelaise 1649-1653», en COCULA, A.-M (ed.): Adhésion et résistences à l'État en France et en Espagne 1620-1660. Pessac, 2001, pp. 111-135.

Ediciones Universidad de Salamanca / @®@@ Stud. his., H. ${ }^{a}$ mod., 41, n. 1 (2019), pp. 153-188 
LOURDES AMIGO VÁZQUEZ

UN NUEVO ESCENARIO DE LA GUERRA CON FRANCIA.

LA INTERVENCIÓN ESPAÑOLA EN LA FRONDA (1648-1653)

los años 1648-1653, no todo estaba ya decidido en la Guerra Franco-Española y cómo la Fronda no fue un «asunto» exclusivamente francés.

\section{1. «ESTAS INQUIETUDES EN FRANCIA» Y «LAS COSAS DE EUROPA»}

En las décadas centrales del siglo XVII, las monarquías francesa y española se enfrentaron militarmente por el predominio en Europa (1635-1659) mientras padecían graves revueltas internas, provocadas por las medidas de política doméstica que implementaban para sostener sus guerras dinásticas. En Francia, sucedieron los tumultos de la Fronda (1648-1653), un movimiento muy complejo, que coincidió con la minoría de edad de Louis XIV, con multitud de protagonistas e intereses diversos, pero con un enemigo común: Mazarin. La Monarquía Hispánica no podía desaprovechar lo que fue considerado un milagro, tal como se estaba desarrollando la guerra. Tras la consulta del Consejo de Estado, el 5 de marzo de 1649, Felipe IV señalaba lo siguiente:

Estas inquietudes en Francia dan motivo para poder esperar den gran buelta las cosas de Europa, principalmente reconociéndose que emanan de la disposición divina, pues en la sazón presente solo ella podía subministrar el único medio para la quietud y reposo de la Christiandad, permitiendo que los movedores del daño que ha recivido sean los que se abrasen en su casa con el fuego que han hecho en las agenas, contra toda razón y justicia ${ }^{12}$.

Los diversos frentes de la contienda se situaban en territorios del rey católico, pero, a finales de la década de 1640, se abría un nuevo escenario: la propia Francia. Se presentaba la ocasión para pagar al reino vecino con la misma moneda, dada su intervención en Cataluña y Portugal y antes en Italia ${ }^{13}$. La Monarquía Hispánica iba a alimentar su guerra intestina para restar todavía más fuerzas al enemigo y tratar así de revertir la situación europea, cada vez más favorable a Francia. Estuvo, de esta forma, pendiente de las revueltas desde sus inicios, en 1648. Ya entró en la Fronda Parlamentaria, en 1649, y, desde el año siguiente, tuvo un destacado papel. Participó en la llamada Fronda de los Príncipes, en 1650, firmando sendas alianzas con Turenne y la duquesa de Longueville (frente septentrional) y con la Princesa de Condé, el duque de Bouillon y demás aliados, refugiados en Burdeos (frente meridional). En noviembre de 1651, rubricó el tratado con Louis II de Bourbon,

12. AGS, Estado, leg. 2071, doc. 33, Consejo de Estado, 5-III-1649.

13. Para la Guerra Franco-Española, a nivel militar, nos remitimos a MAFFI, D.: En defensa...

Ediciones Universidad de Salamanca / @®@@ Stud. his., H. ${ }^{a}$ mod., 41, n. 1 (2019), pp. 153-188 
LOURDES AMIGO VÁZQUEZ

UN NUEVO ESCENARIO DE LA GUERRA CON FRANCIA.

LA INTERVENCIÓN ESPAÑOLA EN LA FRONDA (1648-1653)

que supondrá la mayor implicación española en dichos tumultos, en la conocida como Fronda de Condé.

Es más, con la Paz de Westfalia (1648), el tiempo de las guerras de religión había pasado y lo que predominaba era la política. De la misma forma que Felipe IV buscaba pactar con la Inglaterra de Cromwell, no había problemas de conciencia por aliarse con los protestantes franceses. Ya en febrero de 1649, ante los sucesos de París, Felipe IV escribía a Leopoldo-Guillermo, su Gobernador en los Países Bajos, encargándole que si fuera posible disponer con «los de la religión reformada sería lo más conveniente, porque la negociación con ellos son las que pueden ser más durables y el medio mejor para tener baja la Francia» ${ }^{14}$. El Consejo de Estado volvía a sentenciar, en marzo, que los medios «más eficazes de tener baja a la Francia y que no rebuelba el mundo y acabe con la religión son los ugonotes y el Parlamento». Pero en esta ocasión, Felipe IV mostró cierta cautela ante la primera opción, mandando formar junta de ministros de estado y de teólogos para discutirla ${ }^{15}$. De nuevo, el 27 de abril, una vez conocido que los nobles, además del Parlamento de París, se habían reconciliado con la Corona francesa, el duque de Medina de las Torres y el marqués de Castel Rodrigo, reunidos en Aranjuez en Consejo de Estado, volvieron a insistir a su majestad que «había que fomentar aquellas guerras civiles y interesar en ellas a quelquiera precio a los ugonotes» ${ }^{16}$.

Ya sin vacilaciones, esta fue considerada, en 1650, como la fórmula idónea para prolongar las revueltas en Francia. El 7 de marzo, Felipe IV escribía al archiduque Leopoldo. Aprobaba las negociaciones que se estaban realizando en Flandes con los «malcontentos», apuntándole que lo más idóneo era que Turenne, protestante, lograra ponerse al frente del partido hugonote. Se trataba, en opinión del monarca, de una cuestión de Estado y de la propia Iglesia, puesto que, los franceses, en sus guerras en Alemania y otros territorios, «han ydo estinguiendo la religión católica y dilatado la heregía (...), después que no han tenido esta diversión dentro de su casa». Eso sí, el archiduque debía consultar primero «con los theólogos más doctos de esos Payses (...) si se puede fomentar el partido de los ugonotes con segura conciencia, pues sin esto no se puede hazer nada» ${ }^{17}$. No pareció haber problema, puesto que el 30 de abril se firmó, en Stenay, el tratado con Turenne. Los hugonotes no se levantaron entonces, pero lo mismo se volverá a intentar, poco después, en el frente meridional de las revueltas.

14. AGS, Estado, leg. 2258, s. f., Felipe IV a Leopoldo-Guillermo, 10-II-1649.

15. Ibid., leg. 2071, doc. 33, Consejo de Estado, 5-III-1649.

16. Ibid., doc. 165, Consejo de Estado, 27-IV-1649.

17. Ibid., leg. 2259, s.f., Felipe IV a Leopoldo-Guillermo, 7-III-1650. En esta decisión tuvo peso la opinión del conde de Peñaranda, plenipotenciario en Münster y que entonces se encontraba en Flandes (Ibid., leg. 2073, doc. 79, Peñaranda a Felipe IV, 28-I-1650).

Ediciones Universidad de Salamanca / @®@@ Stud. his., H. ${ }^{a}$ mod., 41, n. 1 (2019), pp. 153-188 
LOURDES AMIGO VÁZQUEZ

UN NUEVO ESCENARIO DE LA GUERRA CON FRANCIA.

LA INTERVENCIÓN ESPAÑOLA EN LA FRONDA (1648-1653)

El barón de Watteville, que llevaba desde San Sebastián y en nombre de Felipe IV las negociaciones con Burdeos, ya informaba el 20 de junio de 1650, que los franceses solicitaban un incremento en el pago inicial, tras la firma del tratado, de 200.000 a 300.000 reales de a ocho. De esta forma entraría en el partido el mariscal de La Force, «que es oy caveça de los ugonotes y hombre de mucho séquito» ${ }^{18}$. La decisión de la corte madrileña fue que primero este noble se declarase ${ }^{19}$. Pero ya en agosto, tras la llegada de Mazerolles a Madrid, enviado por la Princesa de Condé y demás confederados, se determinó aumentar dicha cantidad, para tratar de «comprar» al mariscal y levantar al partido hugonote, «que sería una de las heridas más nocivas que se podrían hazer a la Corona de Francia» ${ }^{20}$. Empero, ni el dinero llegó a Burdeos ni La Force se unió a la Fronda de los Príncipes.

Pese a explorarse nuevas vías, la intervención española en los problemas internos de Francia siguió la que hasta entonces venía siendo la fórmula habitual. El maestro de campo Gabriel de Toledo, encargado de ajustar el tratado con Turenne y la duquesa de Longueville, recordaba a Agustín Navarro, secretario de Estado y de Guerra en Flandes, negociaciones anteriores, no precisamente provechosas:

Haviendo visto un conde de Suison (sic), príncipe de la sangre, formar un partido con nosotros, cuyo tratado tardó seis meses en ajustarse, sin que le siguiese más que un solo cavallero de toda Francia. Después de su muerte se trató con el duque de Guisa, hombre insulso, y se tuvo por gran negocio ajustar con él a costa de una alteza impropia y cinco mil escudos de sueldo cada mes, sin haver sacado la menor conveniencia. Últimamente se introdujo y adelantó plática con el duque de Orliens (sic) y monsiur de Saintmardt (sic), y todas las ventajas eran por su parte dellos, que se perdieron inocentemente ${ }^{21}$.

Se refería a las conjuraciones del duque de Soissons (1641) y Cinq-Mars (1642), con Louis XIII y Richelieu. Hasta el triunfo del Absolutismo, no solo era un derecho sino incluso un deber de la nobleza francesa el rebelarse contra los manipuladores de la autoridad real, que ponían en peligro la salud del reino y, con ello, los privilegios del estamento nobiliario. Un «deber de revuelta» que no escatimaba el uso de la violencia ni la alianza con el extranjero y especialmente con la Monarquía Hispánica,

18. Ibid., leg. 2074, doc. 26, Watteville a Felipe IV, 20-VI-1650. Como se comprobará, en la documentación consultada se tiende a utilizar indistintamente y con el mismo valor los escudos y los reales de a ocho (también llamados patacones), debido a su conversión en moneda francesa. Si bien un escudo eran 340 maravedíes y un real de a ocho solo 272.

19. AGS, Estado, Leg. 2074, doc. 25, Junta de Estado, 24-VI-1650.

20. Ibid., doc. 61, Junta de Estado, 4-VIII-1650.

21. Ibid., leg. 2073, doc. 131, Gabriel de Toledo a Agustín Navarro, 23-IV-1650.

Ediciones Universidad de Salamanca / @®@@ Stud. his., H. ${ }^{a}$ mod., 41, n. 1 (2019), pp. 153-188 
LOURDES AMIGO VÁZQUEZ

UN NUEVO ESCENARIO DE LA GUERRA CON FRANCIA.

LA INTERVENCIÓN ESPAÑOLA EN LA FRONDA (1648-1653)

dado su poder y su rivalidad con la Corona francesa ${ }^{22}$. En este sentido, tampoco hay que olvidar la existencia de un partido devoto, heredero de la Liga y partidario de la paz con la casa de Habsburgo ${ }^{23}$. Fueron, de esta forma, miembros de la alta nobleza, ahora contra Mazarin, quienes buscaron la protección y sellaron alianzas con Felipe IV, en 1650 y 1651. Un proceder que, con algunos matices, también se había seguido en las denominadas Frondas Parlamentarias.

El 19 de febrero de 1649, en su segundo viaje a París, fray José Arnolfini, enviado por los ministros de Flandes para tratar con los frondistas, logró hablar ante el Parlamento ${ }^{24}$. Aun así, la actitud de este siempre fue difusa. A nivel institucional, como compañía, nunca apoyó abiertamente la intervención española, aunque tampoco se opuso. Incluso, según escribía Arnolfini, antes de comenzar las conversaciones con Mazarin en Rueil, los diputados del Parlamento le habían señalado que «si podría dar palabra de que vuestra alteza [el archiduque] les socorrería dentro de doze o catorze días sin falta no harían la conferencia» ${ }^{25}$. De todas formas, la iniciativa y el control en las negociaciones con Leopoldo-Guillermo, que se desarrollaron entre enero y marzo, fue de la nobleza (que se había aliado con el Parlamento en diciembre de 1648), con un papel muy destacado de personajes como el duque de Bouillon y el futuro cardenal de Retz ${ }^{26}$.

En el caso de Burdeos, aunque los contactos ya se habían iniciado meses atrás, fue en diciembre de 1649 cuando llegó a Madrid un enviado de los generales del ejército del Parlamento, los marqueses de Lusignan y Sauveboeuf, solicitando ayud ${ }^{27}$. De esta forma, tuvo lugar el primer viaje de Watteville a la ciudad francesa, si bien ya entonces se estaba negociando o incluso se había firmado la paz. De nuevo, fueron dos nobles los que encabezaron las frustradas conversaciones, a la vez que la responsabilidad del Parlamento aparece desdibujada. Es más, terminada la Fronda,

22. ARLETTE, J.: Le devoir de révolte. La noblesse française et la gestation de l'État moderne, 1559-1661. París, 1989.

23. GUTTON, J.-P.: Dévots et société an XVIIe siècle. París, 2004.

24. VINCART, J.A.: Relación de los sucesos de las armas de su majestad católica (...) de la campaña y año de 1649, en Biblioteca Nacional de España, mss. 3132, fols. 8r-8v; RETZ, Cardenal de: Mémoires. París, 2010 (ed. S. Bertière), pp. 430-436.

25. AGS, Estado, leg. 2071, doc. 102, Arnolfini a Leopoldo Guillermo, 4-III-1649.

26. Aunque Jean-François-Paul de Gondi, todavía coadjutor de París, trató de presentarse como el interlocutor entre la nobleza, el Parlamento y el pueblo de París, pertenecía al mundo de los grandes, a la más alta nobleza. Vid. PERNOT, M.: «Le rôle politique du cardinal de Retz pendant la Fronde», XVIIe Siècle, 192, 1996, pp. 623-632.

27. LONCHAY, H. et al. (ed.): Correspondance de la cour d'Espagne sur les affaires des Pays-Bas an XVIIe siècle. Bruselas, 1933, vol. 4, pp. 158-159 (Felipe IV a Leopoldo-Guillermo, 2-I-1650).

Ediciones Universidad de Salamanca / అ@@ Stud. his., H. ${ }^{a}$ mod., 41, n. 1 (2019), pp. 153-188 
LOURDES AMIGO VÁZQUEZ

UN NUEVO ESCENARIO DE LA GUERRA CON FRANCIA.

LA INTERVENCIÓN ESPAÑOLA EN LA FRONDA (1648-1653)

este último trató, al igual que la Villa, de desvincularse totalmente de las mismas ${ }^{28}$. Similar comportamiento tuvo lugar los años siguientes: a nivel colectivo, ni el Parlamento, como tampoco la Villa ni l'Ormée, se implicarán en las alianzas con España.

Y es que, tanto en París como en Burdeos, dado el sentimiento antiespañol generalizado, había recelo por tratar con el principal enemigo de la Corona francesa $^{29}$, pero también temor a las posibles represalias de esta, por incurrir en alta traición ${ }^{30}$; circunstancias más fáciles de sortear por la nobleza, habituada, además, a este tipo de negociaciones, que encajaba perfectamente en el código feudal. La situación era distinta a nivel individual. En consecuencia, Watteville no desatendió algo tan necesario para fortalecer la posición española en Burdeos como la compra de lealtades. Desde San Sebastián, en agosto de 1650, señalaba que «me pareció forçoso y muy a propósito ganar los cabos del pueblo de Burdeos, particularmente los jurados nuebos por medio de los viejos (...), y por esta razón (...) e remitido y repartido entre ellos por bía de Bayona asta diez mil escudos franceses ${ }^{31}$. Ya desde Talmont, donde se encontraba con la armada enviada al Príncipe de Condé, el 10 de diciembre de 1651, escribía a Felipe IV:

En Burdeos, los mal afectos empiezan a murmurar que hemos empezado [los españoles] mostrando puntualidad, pero que será como el año pasado, porque aunque queramos no podemos y que con estos engaños vamos entreteniendo para no perdernos solos, y otras impertinencias semejantes, a las quales responden nuestros amigos, que para conserbarlos ha sido forçoso repartir 2.000 escudos entre el Presidente Dafis (sic) y los consejeros La Lemne (sic) y La Bort (sic), y pretenden que esto dure todos los meses ${ }^{32}$.

De nuevo, el 31 de octubre de 1652, Watteville señalaba el reparto de dinero «entre l'Ormea y consegeros de Burdeos» ${ }^{33}$.

Por lo escrito hasta el momento, se deduce que la Monarquía Hispánica tendrá dos vías de intervención en el país vecino, dirigidas a alimentar cada uno de los frentes principales de las revueltas. La primera, a través de los Países Bajos meridionales, lugar frecuente de refugio y de negociaciones con los «malcontentos»

28. Archives historiques du département de la Gironde. París y Burdeos, Chez Aug. Aubry, Libraire y Chez E.G. Gounouilhou, 1861-1862, vol. 3, pp. 380-382 (M. de la Vie a Mazarin, Burdeos, 31-I-1650).

29. RETZ, Mémoires..., pp. 428 y ss., insiste en este hecho, así como en que el Parlamento de París no apoyó a los generales en su pretensión de buscar el apoyo español.

30. Así lo pone de manifiesto el Parlamento de Burdeos, en 1650. LENET, P.: Mémoires. París, 1838 (ed. Michaud y Poujoulat), pp. 314.

31. AGS, Estado, leg. 2074, doc. 88, Watteville a Felipe IV, 12-VIII-1650.

32. Ibid., leg. 2077, doc. 105, Watteville a Felipe IV, 10-XII-1651.

33. Ibid., leg. 2079, doc. 230, Watteville a Felipe IV, 31-X-1652.

Ediciones Universidad de Salamanca / @®@@ Stud. his., H. ${ }^{a}$ mod., 41, n. 1 (2019), pp. 153-188 
LOURDES AMIGO VÁZQUEZ

UN NUEVO ESCENARIO DE LA GUERRA CON FRANCIA.

LA INTERVENCIÓN ESPAÑOLA EN LA FRONDA (1648-1653)

franceses, dada su cercanía a París. Desde allí y estrechamente vinculado con el frente de Flandes de la Guerra Franco-Española, se actuará en el polo septentrional de la Fronda, es decir, en la capital y territorios cercanos a la frontera NE de Francia. La segunda, a través de la Península, con un destacado papel de San Sebastián, plaza naval y comercial, y de su principal puerto, Pasajes, para intervenir en el frente meridional, con capital en Burdeos, muy próxima, por mar, a la ciudad guipuzcoana ${ }^{34}$. De todas formas, Madrid tratará, sobre todo a partir de 1651, de que exista cierta coordinación entre ambas, como la había entre los propios frondistas ${ }^{35}$.

Detengámonos en lo acaecido tras la prisión de los príncipes de Condé y de Conti y duque de Longueville, en enero de 1650, que daba lugar a la Fronda de los Príncipes. El 14 de febrero, conocida la noticia, la Junta de Estado, en Madrid, determinó escribir al archiduque Leopoldo, para «advertirle y encargarle que haga todos los esfuerzos posibles para encender y acrecentar este fuego, ofreciéndoles y ayudándoles [a los rebeldes] con cuanto fuere menester para este fin» ${ }^{36}$. Bruselas ya estaba en ello. Como se escribía a su majestad, el 28 de enero, se había resuelto que fuera alguien a tratar con Turenne y con la duquesa de Longueville ${ }^{37}$. El 8 de febrero se informaba que la duquesa ya había enviado un representante a Bruselas, solicitando hacer tratado, y que Turenne ya había pedido armas y dinero ${ }^{38}$. Aquella era una Monarquía Compuesta o Policéntrica y sus piezas tenían que trabajar de forma armónica. Durante los años de la Fronda, las autoridades de Flandes gozaron de un importante grado de autonomía en sus decisiones y acciones, dada la distancia entre Madrid y Bruselas ${ }^{39}$. En cambio, la actuación de

34. Falta saber si los contactos con Watteville y el primer viaje de este a Burdeos, durante la Fronda Parlamentaria, se realizaron desde San Sebastián.

35. Ya durante la Fronda de los Príncipes, en 1650, se intentó, desde Madrid, cierta coordinación. El archiduque Leopoldo no solo fue constantemente informado de cómo iban las negociaciones en Burdeos. En julio, Felipe IV le ordenaba que el ejército de Flandes actuase tanto para aprovechar la coyuntura en la recuperación de plazas como para hacer diversión en Francia y ayudar, de esta forma, a la parte de Burdeos (AGS, Estado, leg. 2259, s.f., Felipe IV a Leopoldo-Guillermo, 9-VII-1650). En agosto le ordenaba el envío de navíos desde Flandes, para Burdeos (Ibid., Felipe IV a Leopoldo-Guillermo, 23-VIII-1650).

36. AGS, Estado, leg. 2073, doc. 62, Junta de Estado, 14-II-1650.

37. Ibid., doc. 73, Leopoldo-Guillermo a Felipe IV, 28-I-1650 (carta recibida el 3-III-1650).

38. Ibid., doc. 75, Leopoldo-Guillermo a Felipe IV, 8-II-1650 (carta recibida el 3-III-1650).

39. La política en Flandes estaba encabezada, entonces, por el archiduque LeopoldoGuillermo, Gobernador y Capitán General, y el conde de Fuensaldaña, Gobernador de las Armas del Ejército de Flandes. Vid. VERMEIR, R.: «Un austriaco en Flandes. El archiduque Leopoldo Guillermo, Gobernador General de los Países Bajos meridionales (1647-1656)», en MARTÍNEZ MILLÁN, J. y GONZÁLEZ CUERVA, R. (coords.): La dinastía de los Austria: las relaciones entre la Monarquía Católica y el Imperio. Madrid, 2011, vol. 1, pp. 583-608. Sobre cómo se desarrollaban las relaciones entre Madrid y Bruselas, vid. ESTEBAN

Ediciones Universidad de Salamanca / @®@@ Stud. his., H. ${ }^{a}$ mod., 41, n. 1 (2019), pp. 153-188 
LOURDES AMIGO VÁZQUEZ

UN NUEVO ESCENARIO DE LA GUERRA CON FRANCIA.

LA INTERVENCIÓN ESPAÑOLA EN LA FRONDA (1648-1653)

la corte española, encabezada por Felipe IV y Luis de $\mathrm{Haro}^{40}$, fue más directa en Burdeos. Asimismo, como no podía ser de otra forma, en Madrid se negoció y firmó el tratado con el Príncipe de Condé, en 1651, que incluía a ambos frentes.

Burdeos fue ganando en protagonismo, hasta convertirse, entre 1651 y 1653 (con la excepción de los meses que Condé estuvo en París), en la capital de la Fronda. Centró, por tanto, durante aquellos años, el interés de la Monarquía Hispánica, que se erigió en un actor destacado en las revueltas. Pero todavía hay más. A través de la red tejida entre Burdeos y San Sebastián se había logrado, nada menos, que la alianza con el Grand Condé. No en balde, en las negociaciones con España reaparecieron viejos interlocutores, como la duquesa de Chevreuse o el duque de Bouillon ${ }^{41}$, que resultaron fundamentales en los primeros episodios de la Fronda. Pero también surgieron nuevos, entre los que sobresalieron el marqués de Lusignan ${ }^{42}$ y el barón de Watteville ${ }^{43}$, del lado francés y español, respectivamente.

Empero, las relaciones no fueron fáciles en absoluto. Desde Bergerac, el Príncipe de Condé se quejaba amargamente a Pierre Lenet, el 4 de febrero de 1652, tras conocer que Watteville solo iba a entregarle, de parte de Felipe IV, 34.000 patacones:

ESTRÍNGANA, A.: Madrid y Bruselas. Relaciones de gobierno en la etapa postarchiducal (1621-1634). Leuven, 2005.

40. Sobre el círculo cortesano en tiempos de Felipe IV y, muy particularmente, la figura de don Luis de Haro, vid. los recientes estudios de VALLADARES, R. (ed.): El mundo de un valido. Don Luis de Haro y su entorno, 1643-1661. Madrid, 2016 y MALCOLM, A.: Royal Favouritism and the Governing Elite of the Spanish Monarchy 1640-1665. Oxford, 2017.

41. Marie de Rohan, duquesa de Chevreuse, protagonista de numerosas intrigas, sobre todo en tiempos de Richelieu, había huido a España, en 1637, y se había exiliado en dos ocasiones en Flandes, entre 1640 y 1643 y entre 1645 y 1649 (COUSIN, V.: Madame de Chevreuse. París, 1862 ( $2^{\mathrm{a}}$ ed.) y POISSON, G.: La duchesse de Chevreuse. París, 1999). Las vinculaciones con España de Frédéric-Maurice de La Tour d'Auvergne, duque de Bouillon y príncipe de Sedan, venían de tiempos de las conspiraciones del duque de Soissons y Cinq-Mars (CONSTANT, J.-M.: Les conjurateurs: le prémier libéralisme politique sous Richelieu. París, 1986).

42. François de Saint-Gelais, marqués de Lusignan, ya intervino en la Fronda de 1649, al frente de las tropas del Parlamento de Burdeos. Pasó al servicio del Príncipe, participando en las siguientes revueltas. Fue condenado a muerte y decapitado en 1656. Vid. DAST DE BOISVILLE, M.: «La Fronde en Guyenne», en Autographes de Personnages Ayant Marqué Dans L'histoire de Bordeaux et de la Guyenne. Burdeos, 1895, p. 167.

43. Carlos de Watteville de Joux, barón de Watteville y conde de Corbière, era originario del Franco Condado. Maestre de campo general, había destacado en el ejército en Italia, antes de ponerse al frente de las actuaciones de la Monarquía Hispánica en la Fronda de Burdeos. Terminadas las turbulencias en Francia, desempeñará, entre otros cargos, el de capitán general de Guipúzcoa y el de embajador, en Inglaterra y en Portugal, falleciendo en Lisboa en 1670. Vid. THIÉRY, «À la découverte...» y SÁNCHEZ MARTÍN, J. L.: «Wattevile de Joux, Carlos», en Diccionario Biográfico Español [http://dbe.rah.es/biografias/49423/carlos-watteville-de-joux].

Ediciones Universidad de Salamanca / @®@@ Stud. his., H. ${ }^{a}$ mod., 41, n. 1 (2019), pp. 153-188 
LOURDES AMIGO VÁZQUEZ

UN NUEVO ESCENARIO DE LA GUERRA CON FRANCIA.

LA INTERVENCIÓN ESPAÑOLA EN LA FRONDA (1648-1653)

Dittes à Vateville que si dans la fin de feuvrier je n'ay mon argent et mes hommes et mes munitions, qu'ils ne doivent pas espeérer daventage à moy; je suis pressé de touts costés; les ennemis m’estreignent; le pais se ruine; je me vois réduit à la dernière nécessité; je n’ay de leur part ny secours ny argent; jugés après cela ce que je dois faire. Pour cette fois cy seulement recevés l'argent, mais protesté que j'ay encore cette considération pour sa majesté catholique, mais qu'après cela n'en auray plus ${ }^{44}$.

A la pésima imagen que los españoles tenían de los franceses, y viceversa, alimentada por décadas de enemistad entre ambas coronas, exacerbada desde 1635, se añadía una explosiva combinación. Por un lado, los frondistas, exigiendo ayuda y ser la prioridad absoluta y, por el otro, la Monarquía Hispánica, con numerosos frentes de guerra abiertos y una complicada situación hacendística y, por tanto, incapaz de cumplir con lo prometido y pactado en los distintos tratados. En consecuencia, las quejas de los franceses fueron constantes. Siempre trataron de mantener las buenas formas con la corte madrileña, puesto que el respaldo español era vital. No pasó lo mismo con los representantes de su majestad sobre el terreno. En 1650, fueron numerosos los problemas con Turenne, en los Países Bajos meridionales, hasta el punto que, en julio, Madrid planteó, como solución, su paso a Burdeos ${ }^{45}$. A finales de 1652, Watteville relataba a Felipe IV sus enfrentamientos, en la capital de la Guyena, con Pierre Lenet y el Príncipe de Conti, que se unían a los existentes en Flandes. «Ya se acordará vuestra majestad - decía - de las quejas que daban del conde de Fuensaldaña y quan contentos estavan de mí. Ahora es todo al revés, porque se alaban mucho del conde y de mí se quejan muchísimo» ${ }^{46}$.

De todas formas, no hay duda que la Monarquía Católica alentó las revueltas en Francia y contribuyó a sostenerlas. Como reconocía el propio Lenet, mano derecha del Príncipe, las promesas realizadas constantemente por Watteville, en 1650, «ne servirent pas peu pendant quelque temps à maintenir le courage des Bordelais: tant l'espérance du profit a de pouvoir sur les hommes» ${ }^{47}$. Pero no solo alimentó de esperanzas huecas a los frondistas. La ayuda, en dinero, hombres, navíos y armas no fue tampoco desdeñable, sobre todo en tiempos de Condé. El 24 de noviembre de 1652, el barón de Watteville informaba que desde septiembre del año anterior se había gastado en el frente meridional de la Fronda más de un millón de reales de a ocho, de los cuales, 550.000 se habían dado al Príncipe y 365.000 se habían empleado en la armada enviada a Burdeos ${ }^{48}$. Por su parte, desde octubre de 1651

44. AUMALE, Histoire des princes..., vol. 6, p. 509 (Condé a Lenet, 4-II-1652).

45. AGS, Estado, leg. 2073, doc. 150, Junta de Estado, 12-VII-1650; Ibid., leg. 2259, s.f., Felipe IV a Leopoldo-Guillermo, 13-VII-1650.

46. Ibid., leg. 2079, doc. 257, Watteville a Felipe IV, 12-XII-1652.

47. LENET, Mémoires..., p. 327

48. AGS, Estado, leg. 2079, doc. 241, Watteville a Felipe IV, 24-XI-1652.

Ediciones Universidad de Salamanca / అ@@ Stud. his., H. ${ }^{a}$ mod., 41, n. 1 (2019), pp. 153-188 
LOURDES AMIGO VÁZQUEZ

UN NUEVO ESCENARIO DE LA GUERRA CON FRANCIA.

LA INTERVENCIÓN ESPAÑOLA EN LA FRONDA (1648-1653)

hasta agosto de 1653, el partido del Príncipe recibió, vía Flandes, solo en cuanto a dinero, unos 700.000 escudos $^{49}$.

No en balde, la alianza con el Grand Condé, héroe de Rocroi y Lens y otrora gran enemigo, marcó un antes y un después en la intervención española en la Fronda, dada la importante ayuda que Felipe IV se obligaba a prestar. Analicemos, pues, con mayor detalle, su desarrollo.

\section{LA MONARQUÍA HISPÁNICA DURANTE LOS PRIMEROS EPISODIOS DE LA FRONDA}

Fue en el otoño de 1648, cuando primero Bruselas y después Madrid tomaron conciencia de las dimensiones del conflicto entre la corte francesa y el Parlamento de París y la posibilidad de aprovecharse del mismo. El archiduque Leopoldo escribía en este sentido a Felipe IV, el 26 de septiembre, enviándole, asimismo, los avisos recibidos desde el reino vecino ${ }^{50}$. Igual hacía, tres días después, el conde de Peñaranda, informado por Francisco de Galarreta, que se encontraba en París, de regreso a España ${ }^{51}$. Estas y otras cartas se verán en la Junta de Estado, el 24 de octubre, el mismo día en que Francia firmaba los Tratados de Westfalia, a los que Mazarin se había visto en buena medida impelido a causa, precisamente, de los problemas de la Fronda ${ }^{52}$. Su parecer, que contó con la anuencia de Felipe IV, era claro: Leopoldo-Guillermo debía poner «particular cuydado en conservar la desunión por todos cuantos medios se pueda (...), valiéndose para ello del parezer de los condes de Peñaranda y Fuensaldaña» ${ }^{53}$. La situación llega a su momento crítico poco después, en enero de 1649, cuando la corte francesa huye a Saint-German-enLaye y el ejército realista, comandado por el Príncipe de Condé, pone sitio a París. Según la orden de su majestad, a 10 de febrero, el archiduque debía contribuir a fomentar los disturbios, «con gran secreto (...), ayudando debajo de mano la parte más flaca». Lo más conveniente, añadía, era "gozar del beneficio destos rumores, procurando el tiempo que duraren de la recuperación de mis plazas perdidas en esos estados, comenzando por Ipré (sic) $»^{54}$. Los acontecimientos, sin embargo, ya se habían precipitado.

49. Ibid., leg. 2186, s.f., Socorros enviados desde España y dinero gastado con el partido del Príncipe, 1651-1653.

50. Ibid., leg. 2069, doc. 86, Leopoldo-Guillermo a Felipe IV, 26-IX-1648.

51. Ibid., doc. 93, Peñaranda a Felipe IV, 29-IX-1648.

52. SONNINO, P.: Mazarin's Quest: The Congress of Westphalia and the Coming of the Fronde. Cambridge y Londres, 2008.

53. AGS, Estado, leg. 2069, doc. 84, Junta de Estado, 24-X-1648.

54. Ibid., leg. 2071, doc. 17, Felipe IV a Leopoldo-Guillermo, 10-II-1649.

Ediciones Universidad de Salamanca / @®@@ Stud. his., H. ${ }^{a}$ mod., 41, n. 1 (2019), pp. 153-188 
A finales de enero, tanto Mazarin como los frondistas recurrieron a Bruselas. Fray José Arnolfini fue enviado a París, para tratar con el Parlamento y los nobles ${ }^{55}$, y Juan Friquet a Saint-Germain, para hacer lo propio con el ministro italiano ${ }^{56}$. Serán las primeras negociaciones las que prosperen. No en vano, desde 1647 se venían desarrollando contactos con la duquesa de Chevreuse y Saint-Ibar ${ }^{57}$, para apoyar a los «malcontentos» y crear turbulencias en Francia ${ }^{58}$. Madrid, que estaba al corriente, había ordenado a Fuensaldaña, en diciembre de 1648, que «las negociaciones de partidos con franceses que hasta ahora se han platicado y las demás que fueren saliendo", corrieran "por vuestro cuydado y mano (...), y al archiduque (...) le comuniquéis lo que desto os pareziere, para tenerle confiado y con entera satisfación ${ }^{59}$. De esta forma, cuando la alta nobleza se alió con el Parlamento y se decidió solicitar la ayuda española, la comunicación con Bruselas ya estaba abierta ${ }^{60}$. Es más, los dos conspiradores mencionados seguirán facilitando los contactos ${ }^{61}$. Mientras, desde París, si bien el Príncipe de Conti, nombrado «Generalísimo de la Fronda», dirigirá oficialmente las negociaciones, sus máximos responsables serán Paul de Gondi-Retz y, sobre todo, Frédéric-Maurice de La Tour d’Auvergne, duque de Bouillon ${ }^{62}$. Este era otro «malcontento» impenitente, con vínculos de amistad con

55. Ibid., doc. 80, Relación del viaje de fray José a París, s.f.; VINCART, J. A.: Relación de los sucesos..., fols. 6v-7v. Fray José salió de Bruselas el 25 de enero y llegó a París el 1 de febrero. Allí fue recibido en el Hôtel de Ville, por el Príncipe de Conti, el duque d'Elbeuf, el coadjutor de París y diputados del Parlamento.

56. AGS, Estado, leg. 2071, doc. 54, Instrucción del conde de Peñaranda a Juan Friquet, 29-I-1649; Ibid., doc. 78, Relación de la Jornada de Juan Friquet a la corte francesa, 9-II-1649. Llegó a Saint Germain y se entrevistó con Mazarin, el 4 de febrero. Lo que quería este último era entrar en negociaciones con España para la firma de la paz, una forma de que Felipe IV no ayudase al Parlamento y se viese obligado, según el tratado de amistad al que se llegaría, de ayudarlo a él, aunque esto último nunca lo llegó a decir abiertamente Mazarin.

57. Henri d'Escars de Saint-Bonnet, señor de Saint-Ibar, estuvo al servicio del conde de Soissons, hasta su muerte (1641), y después participó en todas las intrigas contra Mazarin.

58. La noticia del primer contacto figura en AGS, Estado, leg. 2067, doc. 224, Consejo de Estado, 7-IX-1647 (se ve una carta de Leopoldo-Guillermo a Felipe IV, del 23-VII-1647, en que le informa). Toda la negociación, que incluía la preparación de una pequeña armada en Flandes para intervenir en La Rochelle, figura en Ibid., leg. 2069. Vid., también, COUSIN, V.: Madame de Chevreuse..., pp. 304 y 525-531.

59. AGS, Estado, leg. 2256, s.f., Felipe IV a Fuensaldaña, 8-XII-1648.

60. RETZ, Mémoires..., pp. 348-349 (sobre las relaciones entre Saint-Ibar, que además era familiar de Gondi, y Fuensaldaña) y pp. 422-423 (sobre el primer viaje de fray José a París).

61. Ibid., destaca el papel como intermediario, entre Madrid y Bruselas, de Saint-Ibar. Sobre el papel de la duquesa de Chevreuse, durante la Fronda Parlamentaria, vid. COUSIN, Madame de Chevreuse..., pp. 312-313.

62. RETZ, Mémoires..., pp. 348 y ss. Vid., también, sobre la actuación de Gondi, TRIBOUT, B.: «Retz et Mazarin: polémique et politique dans les 'Mémoires' de Retz», Studi Francesi, 170 (57, 2), 2013, p. 242. 
LOURDES AMIGO VÁZQUEZ

UN NUEVO ESCENARIO DE LA GUERRA CON FRANCIA.

LA INTERVENCIÓN ESPAÑOLA EN LA FRONDA (1648-1653)

la duquesa de Chevreuse y habituado a negociar con España desde la conspiración del conde de Soissons ${ }^{63}$.

Arnolfini hizo un segundo viaje a París, donde permanecerá hasta el fin de la Fronda Parlamentaria ${ }^{64}$. Por su parte, se sucedieron los enviados de los nobles a Flandes, entre ellos, el propio Saint-Ibar y el marqués de Noirmoutier. Los frondistas querían una rápida intervención del ejército español en Francia, para romper el sitio de París. Pero las autoridades de Bruselas se resistían, por la falta de garantías, ya que prácticamente todo, incluida la participación del Parlamento, sería negociado a posteriori. Además, el 11 de marzo, este ya firmó la Paz de Rueil. Aun así, Fuensaldaña penetró en Francia, con vistas a socorrer la capital, cuando se llegara a un acuerdo $^{65}$. Por fin, el 28 de marzo, en Landrecies, Leopoldo-Guillermo rubricó un tratado con el marqués de Noirmoutiers, que actuaba en nombre de Conti. Pero quedó sin efecto, puesto que, como informaba amargamente el primero a su majestad, por carta del 5 de abril, los príncipes ya se habían ajustado enteramente con la corte francesa:

Ellos han obrado de sus acostumbradas artes y yo me he gobernado por los consejos que parecían más adequados al tiempo presente, esperando que o uniéndome con el partido de los príncipes o llegando a una tratación pudiera conseguir más fácilmente el buen efecto de una paz ygual y durable. No lo ha permitido el leve proceder de estos hombres, con que será forçoso el volver el ánimo a la recuperación de alguna plaza de consequencia en los Payses de vuestra magestad, pareciendo (...) encaminarme azia Ypré $(\text { sic })^{66}$.

Así se hizo, lográndose la recuperación de diversas plazas y, sobre todo, de Ypres, el 8 de mayo ${ }^{67}$. Terminaba, de esa forma, la Fronda en París. Pero consciente

63. También, durante su exilio en Roma, al servicio del Papa, había vuelto a tratar con la Monarquía Hispánica, con vistas a nuevos tumultos en Francia, en 1645-1646. AGS, Estado, leg. 2065.

64. AGS, Estado, leg. 2071, doc. 82, Papel de Peñaranda a Leopoldo Guillermo (instrucción para fray José Arnolfini en su segundo viaje a París), 10-II-1649; Ibid., doc. 87, Arnolfini a Fuensaldaña, 26-II-1649; Ibid., doc. 88, Arnolfini a Fuensaldaña, 23-II-1649; Ibid., doc. 102, Arnolfini a Fuensaldaña, 4-III-1649; Ibid., doc. 104, Arnolfini a Fuensaldaña, 11-III-1649.

65. Ibid., doc. 79, Puntos propuestos por el enviado del Príncipe de Conti, tras el primer viaje de Arnolfini a París, 9-II-1649; Ibid., doc. 86, Lepoldo-Guillermo a Felipe IV, 4-III-1649; Ibid., doc. 95, Fuensaldaña a Felipe IV, 5-III-1649; Ibid., doc. 101, Leopoldo-Guillermo a Felipe IV, 14-III-1649; Ibid., doc. 105, Leopoldo-Guillermo a Felipe IV, 31-III-1649; Ibid., doc. 106, Papel que dieron a Leopoldo-Guillermo Saint-Ibar y el duque de Noirmoutiers, 15-III-1649; Ibid., doc. 107, Respuesta de Leopoldo-Guillermo al papel de Saint-Ibar y Noirmoutiers, 15-III-1649; Ibid., doc. 115, Ajustamiento con Saint-Ibar, s.f. (4-III-1649); Ibid., doc. 174, Fuensaldaña a Felipe IV, 3-IV-1649.

66. Ibid., doc. 172, Leopoldo-Guillermo a Felipe IV, 5-IV-1649.

67. MAFFI, En defensa..., p. 113. 
LOURDES AMIGO VÁZQUEZ

UN NUEVO ESCENARIO DE LA GUERRA CON FRANCIA.

LA INTERVENCIÓN ESPAÑOLA EN LA FRONDA (1648-1653)

de que las aguas seguían revueltas, la consigna de Madrid a Bruselas no podía ser otra que la de «fomentar las turbaciones de la Francia por todos los medios que se pudieren conducir al intento» ${ }^{68}$. Y ese mismo año, aunque por el sur, volverá a presentarse una nueva oportunidad.

Son escasas las noticias sobre el papel de la Monarquía Católica en la revuelta en Burdeos, dirigida principalmente contra el gobernador de la provincia, el duque d'Épernon, que se inició en marzo de 1649. Antes de junio, los rebeldes ya estaban en conversaciones con el barón de Watteville, aunque desconocemos el porqué de la elección de este personaje ${ }^{69}$. Fue en diciembre cuando hizo su primer viaje a la ciudad francesa, ante la solicitud de ayuda por parte de Lusignan y Sauveboeuf ${ }^{70}$. Pero Burdeos ya firmó la paz con Mazarin, el 26 de diciembre. Watteville regresó a España, en enero de 1650, no sin antes estrechar relaciones con diversos personajes ${ }^{71}$. En palabras de Lenet, con el que acabará enemistándose durante la Fronda de Condé, «il semoit de l'argent à tous ceux qu'il croyoit pouvoir l'entretenir» ${ }^{72}$.

En definitiva, en 1649, la Monarquía Hispánica no había pasado de la fase de negociación con los frondistas. Pero se habían establecido unas vías de comunicación que serán utilizadas, ya de manera fructífera, poco después. El 18 de enero de 1650 tuvo lugar la prisión de Louis II de Bourbon, primer príncipe de sangre y el único capaz de hacer frente a Mazarin, junto con su hermano, el Príncipe de Conti, y su cuñado, el duque de Longueville (que habían participado en las revueltas anteriores). De esta manera, entró en la Fronda el numeroso y poderoso clan Condé ${ }^{73}$, al que se unieron otros «malcontentos», como el duque de Bouillon y su hermano, el mariscal Turenne (también presentes en 1648-1649), que se convertirán en sus jefes militares $^{74}$. A su frente se pusieron dos mujeres, la esposa del Príncipe y su hermana,

68. AGS, Estado, leg. 2071, doc. 166, Consejo de Estado, 26-IV-1649.

69. Archives historiques..., 1863, vol. 4, p. 356 (M. Constant a Mazarin, Pons, 1-VI-1649).

70. Pese a lo señalado por THIÉRY, «Â la découverte...», p. 40, Watteville solo hizo tres viajes a la zona de Burdeos, siendo el primero en diciembre de 1649. AGS, Estado, leg. 2079, doc. 246, Watteville a Felipe IV, 5-XII-1652.

71. Archives historiques..., vol. 3, p. 371 (M. de la Vie a Mazarin, Burdeos, 17-I-1650), pp. 375-376 (M. du Plessis a Mazarin, Burdeos, 24-I-1650), pp. 380-382 (M. de La Vie a Mazarin, Burdeos, 31-I-1650), pp. 382-383 (duque d'Épernon a Mazarin, Burdeos, 2-II-1650), pp. 384-386 (duque d'Épernon a Mazarin, Burdeos, 8-II-1650).

72. LENET, Mémoires..., p. 293.

73. Nos remitimos BÉGUIN, Les princes..., pp. 23-146, quien también destaca una de las debilidades del Grand Condé: tanto entonces, en la Fronda de los Príncipes, como después, en la Fronda de Condé, una parte de su clientela tradicional, que había logrado ascender precisamente por la lealtad del Príncipe a la Corona, no estuvo dispuesta a rebelarse contra esta.

74. BÉRENGER, Turenne..., pp. 285-306.

Ediciones Universidad de Salamanca / @®@@ Stud. his., H. ${ }^{a}$ mod., 41, n. 1 (2019), pp. 153-188 
la duquesa de Longueville, quien ya había desempeñado un papel muy activo en los disturbios anteriores ${ }^{75}$. Ambas solicitarán el socorro de España.

El 4 de mayo de 1650, Anne-Geneviève de Bourbon, duquesa de Longueville, se dirigía por carta a Felipe IV. «Je serois indigne - decía - de la protection que vostre majesté m’a acordée pour messieurs mes frères et pour monsieur mon mary sy je concevois moins de recognaisance que je n'en ay pour une sy extraordinaire bonté» ${ }^{76}$. El 6 de mayo, hacía lo propio Henri de la Tour d'Auvergne, vizconde de Turenne, insistiendo en que «suivant l'engagement que i'ay en cette affaire $j$ 'y employeray tout ce qui dépendra de moy» ${ }^{77}$. Acababan de sellar su acuerdo con la Monarquía Hispánica. Tras intentar, sin éxito, sublevar la Normandía, de la que su marido era gobernador, la duquesa de Longueville había recalado en Stenay, plaza del Príncipe de Condé, logrando la alianza con Turenne. Ambos, desde un principio, buscaron pactar, al igual que las autoridades de Bruselas, que tenían el beneplácito de Madrid. Pero las negociaciones, de las que se encargó, por la parte española, Gabriel de Toledo, fueron largas ${ }^{78}$. El 30 de abril, se firmaba el tratado de Stenay, inmediatamente enviado a Madrid y ratificado por Felipe IV ${ }^{79}$. En el mismo, quedaba claro quién era el enemigo común, Mazarin. Ambas partes se comprometían a unir sus fuerzas hasta lograr la firma de la paz entre las dos coronas y la libertad de los príncipes. La Monarquía Hispánica debía proporcionar una importante ayuda económica y militar a Turenne y a la duquesa de Longuevilla, quienes, como garantía, ponían la plaza de Stenay, con la excepción de su ciudadela, en la que ya entró de inmediato una guarnición española ${ }^{80}$.

75. VERGNES, Les frondeuses..., pp. 173-189 y 319-322.

76. AGS, Estado, Leg. 2072, doc. 177, Duquesa de Longueville a Felipe IV, 4-V-1650.

77. Ibid., doc. 179, Turenne a Felipe IV, 6-V-1650.

78. AGS, Estado, leg. 2073, doc. 114, Instrucción de Peñaranda a Gabriel de Toledo, febrero 1650; Ibid., doc. 120, Gabriel de Toledo a Turenne, 26-III-1650; Ibid., doc. 121, Turenne a Gabriel de Toledo, 30-III-1650; Ibid., doc. 119, Gabriel de Toledo a Turenne, 1-IV-1650; Ibid., doc. 122, Duquesa de Longueville y Turenne a Gabriel de Toledo, 1-IV-1650; Ibid., doc. 123, Duquesa de Longeville y Turenne a Gabriel de Toledo, 1-IV-1650; Ibid., doc. 124, Gabriel de Toledo a Fuensaldaña, 1-IV-1650; Ibid., doc. 126, Fuensaldaña a Gabriel de Toledo, 5-IV-1650; Ibid., doc. 127, Fuensaldaña a Gabriel de Toledo, 8-IV-1650; Ibid., doc. 129, Fuensaldaña a Gabriel de Toledo, 12-IV-1650; Ibid., doc. 131, Gabriel de Toledo a Agustín Navarro, 23-IV1650; Ibid., doc. 130, Fuensaldaña a Gabriel de Toledo, 24-IV-1650.

79. Ibid., leg. 2259, s.f., Felipe IV a Leopoldo-Guillermo, 3-VI-1650.

80. «Tratado de alianza entre el señor rey cathólico don Phelipe IV y la señora duquesa de Longueville y el mariscal de Turena». Figura en ABREU Y BERTODANO, J. A. DE: Colección de los tratados de paz [...]. Reinado de Phelipe IV. Parte VI. Madrid, 1751, pp. 41-46. La ayuda española se concretaba en: 200.000 escudos, en dos pagas, tras la firma el tratado; 40.000 escudos mensuales, para el mantenimiento de las tropas, durante los 6 meses de campaña, y 20.000 escudos mensuales, el resto; 60.000 escudos anuales, para asuntos particulares de Turenne y la duquesa de Longueville; 2.000 infantes y 3.000 jinetes, armados.

Ediciones Universidad de Salamanca / అ@@ Stud. his., H. ${ }^{a}$ mod., 41, n. 1 (2019), pp. 153-188 
LOURDES AMIGO VÁZQUEZ

UN NUEVO ESCENARIO DE LA GUERRA CON FRANCIA.

LA INTERVENCIÓN ESPAÑOLA EN LA FRONDA (1648-1653)

La revuelta no logró en el norte de Francia el apoyo esperado, aunque no faltaban personajes conocidos, como Saint-Ibar ${ }^{81}$. En junio, el archiduque LeopoldoGuillermo señalaba que, "por este partido, por hasta ahora, no se ha declarado ninguna persona de calidad ni la menor ciudad de Francia, ni menos ha venido algún regimiento y gente de guerra a incorporarse con Turena, como daba esperanzas que sucedería en entrando nosotros en Francia». Asimismo, decía, su ejército «todo consiste en 1.200 infantes y 400 cavallos» ${ }^{82}$. En octubre, insistía en que «tiene el vizconde mucho menor séquito del que creya, no haviéndosele juntado ningún francés que sea persona de crédito, después de nuestra entrada en la Francia» ${ }^{83}$. En consecuencia, el mariscal dependía básicamente de la ayuda española. Sus tropas contaron con los 5.000 hombres que debía darle Felipe IV. En cuanto al dinero, es difícil contabilizar el que recibió, aunque fue menos de lo pactado. Así, en diciembre de 1650, Leopoldo-Guillermo informaba de «la instancia que hacía el marischal de Turena para que se le pagasen cien mil escudos que se le devían, según lo capitulado con él» ${ }^{84}$.

Pronto surgieron los conflictos entre Turenne y los ministros de Flandes. El primero exigía ser tratado «como a hermano segundo de príncipe del Imperio soberano", razón por la que el archiduque había solicitado su parecer al emperador ${ }^{85}$. En cuestiones de protocolo, la decisión de Felipe IV fue recordarle a su primo «lo mucho que conviene ir con cuydado de no disgustar al mariscal por esto ni desconcertarse con él» ${ }^{86}$. Pero Turenne también reclamaba que el ejército de Flandes penetrara en Francia y estuviera completamente subordinado a sus intereses, a lo que ya no se mostró tan solícito el monarca, habida cuenta de las escasas tropas que el francés había logrado movilizar ${ }^{87}$. De todas formas, gracias a las operaciones de este y del ejército de Flandes, la de 1650 fue una buena campaña para la Monarquía Hispánica,

81. LENET, Mémoires..., p. 316.

82. AGS, Estado, Leg. 2073, doc. 151, Leopoldo-Guillermo a Felipe IV, 25-VI-1650. Estas cifras prácticamente coinciden con las señaladas por el contador Diego de Hernani, tras realizarse la muestra del ejército de Flandes, en junio; señalaba que estaba compuesto, entre infantería y caballería, de 8.191 oficiales y 22.615 soldados, y que las tropas de Turenne serían otros 1.500 hombres, entre infantería y caballería (Ibid., leg. 2172, s.f., Diego de Hernani a Felipe IV, 3-VI-1650).

83. Ibid., leg. 2073, doc. 246, Leopoldo-Guillermo a Felipe IV, 14-X-1650.

84. Ibid., leg. 2259, s.f., Leopoldo-Guillermo a Felipe IV, 29-XII-1650.

85. Ibid., leg. 2072, doc. 164, Leopoldo-Guillermo a Felipe IV, 2-VI-1650.

86. Ibid., leg. 2261, s.f., Felipe IV a Leopoldo-Guillermo, 9-VII-1650.

87. Ibid., leg. 2073, doc. 151, Leopoldo-Guillermo a Felipe IV, 25-VI-1650; Ibid., doc. 152, Turenne a Fuensaldaña, 11-VI-1650; Ibid., leg. 2059, s.f., Felipe IV a Leopoldo-Guillermo, 13-VII-1650.

Ediciones Universidad de Salamanca / అ@@ Stud. his., H. ${ }^{a}$ mod., 41, n. 1 (2019), pp. 153-188 
en aquel frente de la Guerra Franco-Española. Si bien, el 13 de diciembre, Turenne sufrió una dura derrota en Rethel ${ }^{88}$.

Por aquel entonces, tuvo lugar la unión de las dos Frondas (la Parlamentaria y la de los Príncipes), que provocó la salida de Mazarin hacia un exilio momentáneo y la liberación de los príncipes, el 13 de febrero de 1651. El día 23, la Junta de Estado ya se hizo eco de la noticia, mostrando su temor a que Turenne y la duquesa de Longueville no cumplieran con lo pactado y se retiraran de la alianza ${ }^{89}$. Y así fue. Como se lamentaba en mayo, el archiduque, «es sin duda que en estos coligados de vuestra magestad no se puede esperar gratitud ninguna. Turena se a ydo a París sin dar aviso de su partida» ${ }^{90}$. Seguía los pasos de la duquesa, que ya había abandonado Stenay en marzo ${ }^{91}$. ¿Qué había pasado mientras tanto en Burdeos?

Tras la prisión de los príncipes, la mayoría de sus partidarios se iban a concentrar en el frente meridional, en la Guyena, donde el clan Condé gozaba de gran prestigio e influencia. La Princesa hizo su entrada en Burdeos el 31 de mayo de 1650 e inmediatamente después, la ciudad proclamó su rebeldía. Sin embargo, las negociaciones con la Monarquía Hispánica habían comenzado antes. El 26 de marzo había sido enviado un gentilhombre, llamado Fanget, con carta de creencia, dirigida al barón de Watteville, firmada por viejos frondistas, como eran los marqueses de Lusignan y Sauveboeuf y el jurado Fonteneil. Según figuraba en su instrucción, «si no hallare al barón de Batevila, en Madrid, habrá de encaminarse derecho al señor don Luis de Haro». Debía representar que los duques de Bouillon, La Rochefoucauld y SaintSimon y los marqueses de Sauveboeuf y Lusignan

están resueltos a formar partido en Guiena y que este será tan poderoso que podrá producir la paz general, que prometen a su magestad católica de no efectuarla sin su gusto y consentimiento. Y para conseguirla se hallan ya asegurados de las mejores plazas de Francia y de la capital desta provincia, que es Burdeos, que sigue el mismo partido, y que se halla en ella el marqués de Lusignan, no dejándola declarar hasta que todas las cosas estén apercibidas.

Debía solicitar que su majestad «se sirva de socorrernos promptamente, con dinero, no habiendo menester de otra cosa, porque gente tendrán toda la que fuere necesario, y que este llegue a la suma de ducientos mil doblones». Esta cantidad iría en un navío al puerto de Saint-Bonnet, muy cercano de Burdeos y Blaye, donde se encontraban, respectivamente, Lusignan y Saint-Simon. En el mismo viajaría un representante de Felipe IV para concluir el tratado, que sería en conformidad al que

88. MAFFI, En defensa..., pp. 116-117.

89. AGS, Estado, leg. 2075, doc. 16, Junta de Estado, 23-II-1651.

90. Ibid., leg. 2261, s.f., Leopoldo-Guillermo a Felipe IV, 6-V-1651.

91. Ibid., leg. 2177, doc. 90, Fuensaldaña a Felipe IV, 1-IV-1651. 
hacían la duquesa de Longueville y Turenne con Leopoldo-Guillermo. Por último, Fanget debía señalar que «entregarán, si fuera necesario, la plaza de Blaya (sic), que es tan importante, y que está en ella el duque de San Simon (sic), a su magestad, para que ponga en ella presidio español, si lo tuviere por bien ${ }^{92}$.

El gentilhombre francés llegó a la capital de la Monarquía en abri193. Felipe IV concedió plenipotencia al barón de Watteville para firmar un tratado y este realizó un nuevo viaje a la Guyena ${ }^{94}$. El 9 de mayo, en La Roque de Thau, pudo hablar con Lusignan, el jurado Fonteneil y un miembro del Parlamento. Pero no se llegó a ningún acuerdo, puesto que Saint-Simon ya había abandonado el partido y Bouillon y La Rochefoucauld no se encontraban en Burdeos. En palabras del barón, «estos hombres oy no tienen seguridad que dar más que su palabra, esta es francesa y suele faltar a menudo (...), y no ostante piden desbergonçadamente por lo menos trecientos mil escudos, para levas, y cinquenta mil cada mes, para las pagas durante la guerra» ${ }^{95}$.

Bouillon y La Rochefoucauld estaban acompañando a la Princesa de camino a Burdeos. El 14 de mayo, cerca de Turenne, ambos fueron informados de lo sucedido en la reunión con el barón de Watteville y ya lograron implicar, en las negociaciones, a la esposa del Príncipe ${ }^{96}$. No en vano, como hemos señalado, Claire-Clémence de Maillé-Brézé se iba a poner al frente del clan Condé y del polo meridional de las revueltas, pero solo de manera nominal y simbólica. Los máximos responsables serían dos nobles, ya presentes en la Primera Fronda: La Rochefoucauld y, sobre todo, Bouillon, con quien la Monarquía Hispánica acababa de negociar el año anterior. A ellos se añadiría, más en la sombra, Pierre Lenet, lugarteniente del Príncipe de Condé, a quien este había encargado la protección de su esposa e hijo ${ }^{97}$.

De vuelta a San Sebastián y con el visto bueno de Madrid, Watteville continuó las conversaciones con diversos personajes, ya enviados en nombre de la Princesa y demás confederados. De nuevo Fanget y Pierre Carroz llegaron antes de su entrada en Burdeos, para informar de la misma ${ }^{98}$. El 20 de junio, Watteville anunciaba

92. Ibid., leg. 2174, s.f., Carta de creencia del gentilhombre francés para Watteville e instrucción, 26-III-1650.

93. Ibid., leg. 2073, doc. 97, Junta de Estado, 11-IV-1650.

94. Ibid., Estado K, leg. 1665, doc. 82, Plenipotencia de Felipe IV a Watteville, 18-IV-1650; Ibid., doc. 84, Instrucción de Felipe IV a Watteville para su jornada a la Guyena, 18-IV-1650.

95. Ibid., Estado, leg. 2074, doc. 3, Watteville a Felipe IV, 13-V-1650.

96. LENET, Mémoires..., p. 265.

97. Sobre este personaje, vid. BÉGUIN, Les princes..., p. 427.

98. AGS, Estado, leg. 2074, doc. 6, Watteville a Felipe IV, 28-V-1650 (informa de la llegada de Fanget); Ibid., doc. 9, Watteville a Felipe IV, 25-V-1650 (llegada de Pierre Carroz); Ibid., doc. 10, Carta de creencia de Pierre Carroz, por la Princesa de Condé y demás confederados, 16-V-1650; Ibid., doc. 11, Lusignan y Fonteneil a Watteville, 20-V-1650 (informan del envío de Carroz).

Ediciones Universidad de Salamanca / @®@@ Stud. his., H. ${ }^{a}$ mod., 41, n. 1 (2019), pp. 153-188 
LOURDES AMIGO VÁZQUEZ

UN NUEVO ESCENARIO DE LA GUERRA CON FRANCIA.

LA INTERVENCIÓN ESPAÑOLA EN LA FRONDA (1648-1653)

el arribo del barón de Baas, estrechamente vinculado al conde de Bouillon, con poderes para firmar una alianza. También habían sido enviados los marqueses de Sillery y Sauveboeuf, pero tuvieron numerosos problemas en atravesar la frontera, por lo que no llegaron a tiempo para las negociaciones ${ }^{99}$. El 26 de junio se firmaba el Tratado de San Sebastián, por el barón de Watteville, en nombre de Felipe IV, y el de Baas, por la Princesa de Condé y los duques de Bouillon y La Rochefoucauld y los marqueses de Sauveboeuf y Lusignan ${ }^{100}$. Era similar al de Stenay, si bien la ayuda se reducía a dinero, ya que los rebeldes no habían pedido hombres y, además, la Monarquía Hispánica tampoco los podía proporcionar, debido a la guerra en Cataluña. Por otra parte, Watteville había sido aleccionado para que en cuanto a las «asistencias de dinero, procure recatear quanto fuere posible por la falta que ay, del que no pudiendo más se convenga dar (...) lo mismo que se ha ofrecido al mariscal Turena» ${ }^{101}$. Tras firmarlo, ya se enviaron a Burdeos cerca de 100.000 reales de a ocho. Fueron llevados, en barco, por el teniente de maestre de campo general José de Vera Osorio, quien volvió a San Sebastián, acompañado del marqués de Sauveboeuf y de Mazerolles ${ }^{102}$.

Osorio también había llevado a Burdeos el tratado. Los frondistas consideraron que no cumplía con sus expectativas y enviaron a Mazerolles, para negociar directamente con Felipe IV ${ }^{103}$. Acompañado del marqués de Sauveboeuf, llegó a Madrid a finales de julio, con carta de la Princesa de Condé para su majestad y otra de Lenet para don Luis de $\mathrm{Haro}^{104}$. Ya entraban, de esta forma, en escena, los criados de Louis II de Bourbon. Mazerolles solicitó el incremento del dinero pactado, puesto que no era suficiente, más aún si en el partido entraba el mariscal La Force. También pedía

armar en San Sebastián y El Pasaje el mayor número de navíos que se pudiera con toda la brevedad y diligencia posible, aunque por ahora no sean más que siete u ocho, pues bastarán para asegurar con las catorce galetas, dos galeras y cuatro navíos que

99. LENET, Mémoires..., pp. 295-299, 308 y 318.

100. AGS, Estado, leg. 2177, doc. 182, Tratado de San Sebastián, 26-V-1650. La ayuda española era la siguiente: 200.000 reales de a ocho, en dos pagas, tras la firma del tratado; 40.000 reales de a ocho mensuales, para el mantenimiento de las tropas, durante los 6 meses de campaña, y 20.000 , el resto; 60.000 reales de a ocho anuales, para asuntos particulares de la Princesa de Condé y el duque de Bouillon; Artillería y municiones. Aunque las monedas eran en reales de a ocho, se señalaba que se trataba de las mismas cantidades que en el Tratado de Stenay, donde eran en escudos.

101. AGS, Estado, leg. 2074, doc. 7, Junta de Estado, 30-V-1650.

102. Ibid., doc. 33, Watteville a Felipe IV, 30-VI-1650; Ibid., doc. 50, Watteville a Felipe IV, 18-VII-1650.

103. LENET, Mémoires..., pp. 312-313; AGS, Estado, leg. 2074, doc. 51, Informe de don José Osorio a su vuelta de Burdeos, s.f. (agosto de 1650).

104. AGS, Estado, leg. 2074, doc. 61, Junta de Estado, 4-VIII-1650.

Ediciones Universidad de Salamanca / @®@@ Stud. his., H. ${ }^{a}$ mod., 41, n. 1 (2019), pp. 153-188 
LOURDES AMIGO VÁZQUEZ

UN NUEVO ESCENARIO DE LA GUERRA CON FRANCIA.

LA INTERVENCIÓN ESPAÑOLA EN LA FRONDA (1648-1653)

tiene armados la Princesa de Condé, la rivera de Burdeos, entretanto que llegue la escuadra que su majestad ha mandado venir a esta parte de poniente ${ }^{105}$.

Madrid estuvo de acuerdo ${ }^{106}$. A la cantidad inicial se añadirían otros 100.000 escudos (sic), ya que la entrada de La Force se consideraba fundamental, para levantar a los hugonotes. En cuanto a los navíos que deberían pasar a Burdeos, esta era una cuestión que ya se había planteado durante las negociaciones del tratado. En la Junta de Estado, celebrada el 31 de mayo, se había determinado que, si lo consideraba conveniente, el barón solicitara el envío desde Flandes de algunos navíos o fragatas, para mantener abierta la ría ${ }^{107}$. El 21 de junio se insistía a Watteville que tratara de reducir las asistencias a dinero, pero que «bien podrá asegurarles que se ha enviado orden a Italia para que pase de esta parte un grueso considerable de la armada naval, el cual se pondrá en San Sebastián para tenerles la comunicación del mar abierta y dar mayor calor y fuerza a sus operaciones ${ }^{108}$. Por su parte el barón, que ya había pedido navíos al archiduque Leopoldo ${ }^{109}$, planteó la necesidad de prevenir algunos en Guipúzcoa ${ }^{110}$. Tras la aprobación de la corte madrileña ${ }^{111}$, se dedicó a su apresto ${ }^{112}$. Ahora, a Mazerolles se le aseguraba el rápido envío a Burdeos del mayor número posible de barcos, desde San Sebastián, y, también, que en breve iría la armada del mar océano. Pero la Monarquía Hispánica no será capaz de cumplir sus promesas.

La situación en la Guyena se fue haciendo cada vez más angustiosa. El partido de los príncipes tampoco consiguió aquí el apoyo esperado. Además, Mazarin centró su atención y el ejército en acabar con la resistencia en esta provincia. Watteville, junto con Baas, Mazerolles y Sillery, que se quedaron en San Sebastián, trataron de mantener los ánimos de los frondistas, asegurándoles que las asistencias españolas llegarían pronto ${ }^{113}$. Aunque solo se habían logrado aprestar 4 navíos y 2 fragatas y reunir 100.000 reales de a ocho, ya a mediados de agosto, Madrid ordenó su partida hacia Burdeos, bajo las órdenes de Watteville ${ }^{114}$. Pero su salida se fue dilatando. Como señalaba el barón, el día 23, los franceses que se encontraban con él no querían embarcarse, «alegando que el partido desmayará, sin duda, si, después de tanto tiempo, nos viesen llegar solamente con quatro navíos, y que, viéndome

105. Ibid., doc. 63, Mazerolles a Felipe IV, s.f. (agosto de 1650).

106. Ibid., doc. 61, Junta de Estado, 4-VIII-1650.

107. Ibid., doc. 7, Junta de Estado, 31-V-1650.

108. Ibid, doc. 15, Junta de Estado, 21-VI-1650.

109. Ibid., leg. 2259, s.f., Leopoldo-Guillermo a Felipe IV, 3-VI-1650.

110. Ibid., leg. 2074, doc. 30, Watteville a Felipe IV, 25-VI-1650.

111. Ibid., doc. 29, Junta de Estado, 28-VI-1650.

112. Ibid., doc. 58, El veedor general Miguel de Necolalde a Felipe IV, 25-VII-1650; Ibid., doc. 59, Relación de las naos y fragatas que se están preparando para Burdeos, 25-VII-1650.

113. LENET, Mémoires..., pp. 333 y siguientes.

114. AGS, Estado, leg. 2074, doc. 87, Junta de Estado, 16-VIII-1650. 
a mí con ellos, no sería posible persuadirlos a que ay mayores disposiciones». Su propuesta, con la que Watteville estaba de acuerdo, era enviar a José de Vera Osorio con los barcos y el dinero ${ }^{115}$. La Junta de Estado, celebrada el 27 de agosto, siguió manteniendo su parecer ${ }^{116}$. Pero, por cartas del día 30, tanto Watteville como el barón de Baas volvían a insistir en que no era conveniente el paso del primero, sino que fuera Osorio acompañado por Baas ${ }^{117}$. Así lo hicieron, el 4 de septiembre, con municiones y dinero, en los 4 navíos, acompañados de 3 fragatillas ${ }^{118}$.

El 19 de septiembre se tuvo noticia, en Madrid, de que los barcos no habían podido entrar en la ría de Burdeos y se habían vuelto a España, puesto que la ciudad ya estaba sitiada por tierra y por mar ${ }^{119}$. La única solución era que pasara lo antes posible la armada del mar océano, que estaba volviendo de Italia, tras la recuperación de Puerto Longon. Mientras tanto, el barón de Watteville debía procurar «introducir avisos en Burdeos, dándoselos de que por horas se está aguardando la armada y alentándoles mucho, pues debe creerse que si los tiempos son favorables que su llegada no podrá dilatarse, haviendo tantos días que navega» ${ }^{120}$. Todavía el 12 de octubre, la corte madrileña daba órdenes para que la armada fuera, sin dilación, hacia San Sebastián ${ }^{121}$. Pero en la Junta de Estado, celebrada el día 18, se determinó que ya se recogiera en La Coruña ${ }^{122}$. Se acababa de saber que, el 1 de octubre, Burdeos había firmado la paz con Mazarin, lo que marcaba el fin de la Fronda, al menos de momento.

\section{LA FRONDA DE CONDÉ ¿Y DE FELIPE IV?}

El 8 de noviembre de 1651, el barón de Watteville escribía a su majestad. Lo hacía desde Talmont, en la ría de Burdeos:

A 19 del pasado (...) salí de El Pasaje, con el troço de la armada que allí se hallaba, navegando en demanda de la ría de Burdeos, en execución de las órdenes de vuestra majestad. Después de muchas variedades del tiempo llegué al cavo de cinco días a la vista de la torre de Cordan (sic) que es la entrada de la ría, sin poder entrar en ella por el estorbo de vientos borrascosos, con lo qual, por no volver a España, sin haver cumplido con lo determinado, me resolví a dar fondo en el dicho parage (...).

115. Ibid., doc. 115, Watteville a Felipe IV, 23-VIII-1650.

116. Ibid., doc. 113, Junta de Estado, 27-VIII-1650.

117. Ibid., doc. 133, Watteville a Felipe IV, 30-VIII-1650; Ibid., doc. 134, Baas a Haro, 30-VIII-1650.

118. Ibid., doc. 139, Watteville a Felipe IV, 4-IX-1650.

119. Ibid., doc. 157, Junta de Estado, 19-IX-1650.

120. Ibid., doc. 167, Junta de Estado, 2-X-1650.

121. Ibid., doc. 176, Junta de Estado, 12-X-1650.

122. Ibid., doc. 180, Junta de Estado, 18-X-1650. 
LOURDES AMIGO VÁZQUEZ

UN NUEVO ESCENARIO DE LA GUERRA CON FRANCIA.

LA INTERVENCIÓN ESPAÑOLA EN LA FRONDA (1648-1653)

Últimamente, mejoró el tiempo, mudóse el viento y entré en la ría, siguiéndome todos los nabíos por el mismo parage ${ }^{123}$.

El tratado con Louis II de Bourbon se había suscrito en Madrid, el 6 de noviembre. ¿Cómo era posible que la armada, que figuraba entre sus cláusulas, ya se encontrara en la ría de Burdeos? La ayuda española a la Fronda de Condé, al igual que la propia revuelta, venía gestándose desde meses atrás. Incluso, podemos decir que, en esta ocasión, la Monarquía Católica llevó buena parte de la iniciativa en las negociaciones. Hay que remontarse a principios de octubre de 1650. Pese a que acababa de suscribirse la paz con la corte francesa, Bouillon, La Rochefoucauld y Lenet no lo daban todo por perdido. Había una posibilidad: sellar una nueva alianza con España, que reactivara la sublevación en el sur. Para ello, Lenet logró que la madrugada del 3 de octubre, antes de su salida de Burdeos, la Princesa de Condé firmara, sin ser consciente de ello, una carta dirigida a Felipe IV, en creencia del marqués de Lusignan ${ }^{124}$.

Watteville informaba de la llegada de este francés a San Sebastián, así como de su partida, hacia Madrid, el 16 de diciembre ${ }^{125}$. Fue en la Junta de Estado, celebrada el día 31, cuando se conoció y se aceptó su propuesta ${ }^{126}$. Comenzaron, así, las negociaciones, que concluyeron el 15 de febrero de 1651, con un nuevo tratado, firmado por el rey y Lusignan, este último en su nombre y en los de la Princesa de Condé, duques de Bouillon y La Rochefoucauld y mariscal La Force. Junto con la ayuda económica, Felipe IV se comprometía a que, desde entonces, estarían prevenidos en San Sebastián 25 navíos, con cuatro mil hombres de guerra, «para acudir a la parte donde se juzgare por más conveniente, para conseguir los fines propuestos, que son la liberación de los señores príncipes y obligar a los enemigos a que vengan en una honesta, justa y durable paz, que ponga en reposo los súbditos de ambas coronas» ${ }^{127}$. Por su parte, los intereses de Lusignan quedaban unidos a los de la Monarquía Hispánica, al concedérsele «mil escudos de pensión al mes durante la guerra y 500 escudos después de pensión por su vida» ${ }^{128}$.

123. Ibid., leg. 2077, doc. 92, Watteville a Felipe IV, 8-IX-1651.

124. LENET, Mémoires..., pp. 408-409.

125. AGS, Estado, leg. 2074, doc. 198, Watteville a Felipe IV, 19-XII-1650.

126. Ibid., doc. 209, Junta de Estado, 31-XII-1650.

127. Ibid., Estado K, leg. 1644, doc. 31. La ayuda española se concretaba en: 25 navíos, con 4.000 soldados (para su guarnición debían entregar un puerto); 300.000 patacones, en dos pagas, tras la firma del tratado; 60.000 patacones mensuales, los dos primeros meses, y 40.000 los restantes, para el mantenimiento de las tropas; 60.000 patacones anuales, para los sueldos de cabos y oficiales del partido.

128. AGS, Estado K, leg. 1644, doc. 29, Memorial de Lusignan soliciando pensión a su majestad, s.f. (1651); Ibid., Estado, leg. 2075, doc. 11, Junta de Estado, 10-II-1651.

Ediciones Universidad de Salamanca / @®@@ Stud. his., H. ${ }^{a}$ mod., 41, n. 1 (2019), pp. 153-188 
La libertad de los príncipes, que tuvo lugar el 13 de febrero de 1651, se conoció en Madrid el día 23. Aun así se consideró que «lo más conveniente será no aflojar en la prevención de la armada, ni en las otras que a fin de ponerla en orden son necesarias»; bien podría utilizarse en Francia o, de lo contrario, aprovecharse para trasladar infantería española a Flandes ${ }^{129}$. El Tratado de Stenay quedó en suspenso, al igual que ya estaba el de San Sebastián, desde la rendición de Burdeos, y tampoco llegó a ratificarse el firmado por Lusignan. Pero habida cuenta de las noticias que venían de Francia, principalmente a través de Watteville y sus confidentes, la corte madrileña no perdía la esperanza de que ahora fuera el propio Condé quien solicitara ayuda. A principios de mayo, ya hubo contactos con el Príncipe a través de Flandes. Para lograr la salida de la guarnición española de Stenay, el marqués de Sillery fue enviado a Bruselas. En palabras de Leopoldo-Guillermo, con quien se entrevistó, su comisión «no se extendió a más que a asegurarle de su parte [de Condé] la gratitud que conservaba de los beneficios recibidos de vuestra magestad, los quales procurará recompensar con promober la paz [entre ambas coronas] con todo calor y eficacia» ${ }^{130}$. En cambio, según el historiador del siglo XIX, Victor Cousin, apoyado en las memorias de La Rochefoucauld, el marqués tenía orden secreta de renovar los tratados firmados en 1650 y saber qué ayuda podría ofrecer España si Condé se veía obligado a rebelarse, a lo que no faltaron las grandes promesas de Fuensaldaña ${ }^{131}$.

De todas formas, el Príncipe sí estaba al corriente de las negociaciones llevadas a cabo por Lusignan. Todavía en prisión, Lenet le había informado de su envío a España, logrando el beneplácito de Condé132. A su vuelta, el propio Lusignan le entregó el tratado, antes de que se produjera el viaje de Sillery a Flandes ${ }^{133}$. A finales de mayo, la armada ya «estaba aprestada en toda forma en el puerto de Pasaje» ${ }^{134}$. En julio, cuando, a través de Watteville, se conocían las disensiones en París entre los frondistas y los pasos que estaba dando Condé, la Junta de Estado consideró que la armada «está bien en el Pasaje y que el Príncipe se ha de persuadir y asegurar que es para asistirle y socorrerle. Y que mediante esto podría ser que adelante y apresurase sus resoluciones y yntento» ${ }^{135}$. Madrid no se equivocaba. El 30 de julio, el marqués de Lusignan, desde Burdeos, ya escribió a Watteville, asegurándole que Condé se

129. Ibid., Leg. 2077, doc. 1, Junta de Estado, 23-II-1651; Ibid., leg. 2261, s.f., Felipe IV a Leopoldo-Guillermo, 26-II-1651.

130. Ibid., leg. 2261, s.f., Leopoldo-Guillermo a Felipe IV, 6-V-1651.

131. COUSIN, V.: Madame de Longueville pendant la Fronde, París, 1881 (6 ed.), pp. 38-39.

132. LENET, Mémoires..., pp. 485-486 y 491.

133. Ibid., p. 525. De esta forma, un ejemplar del tratado se localiza en Archives du musée Condé au Chateau de Chantilly [en adelante AC], série P., vol. 10, fols. 22-24.

134. AGS, Estado, leg. 2261, s.f., Felipe IV a Leopoldo-Guillermo, 28-V-1651.

135. Ibid., leg. 2077, doc. 25, Junta de Estado, 23-VII-1651. 
declararía en contra de Mazarin y solicitaría la ayuda de Felipe IV, en particular, los navíos ${ }^{136}$. Se reiniciaron de esta forma los contactos. Es más, a partir del 10 de septiembre, Lusignan ya hablará en nombre del Príncipe ${ }^{137}$.

El Grand Condé abandona París el 6 de septiembre de 1651, un día antes de la proclamación de la mayoría de edad de Louis XIV. Llega a Burdeos, el día 22, ahora como gobernador de la provincia ${ }^{138}$. Comienza la llamada Fronda de Condé, ya sabedor el Príncipe de que contaba con el apoyo español. Una circunstancia en absoluto baladí y que de alguna forma bien pudo influir en su decisión de rebelarse contra el rey de Francia. El 27 de septiembre, Madrid dio luz verde para que cuando recibiera el aviso de Condé, Watteville partiera rumbo a Burdeos, con los barcos y el dinero que estaban en San Sebastián ${ }^{139}$. El 6 de octubre llegó Pierre Lenet a la ciudad guipuzcoana, con dicha orden ${ }^{140}$. En consecuencia, la armada salió con el primer buen tiempo, el 19 de octubre.

Fue el 16 de septiembre, en Montrond, donde Louis II de Bourbon se había reunido con sus más fieles seguidores, cuando se decidió el envío de Lenet a España. Al mismo tiempo, La Roque, familiar del Príncipe, se dirigió a los Países Bajos católicos ${ }^{141}$. No en vano, puesto que la ayuda española por el sur ya se daba por segura, era necesario revitalizar, lo antes posible, la proveniente de Flandes. La Roque firmó un nuevo tratado con el archiduque, en Maubeuge, el 26 de octubre ${ }^{142}$, si bien sus cláusulas quedarán recogidas en el que ya, con un carácter general, será suscrito por Lenet, el 6 de noviembre. Según el Tratado de Madrid, el enemigo común no era Louis XIV sino Mazarin. Ambas partes se comprometían a mantener la alianza hasta que se lograse la paz entre las dos coronas y, con ella, la satisfacción de los intereses de Condé. Asimismo, la Monarquía Hispánica se obligaba a proporcionar importantes asistencias, para impulsar la revuelta en el norte y sur: 5.000 hombres y artillería, en la frontera de los Países Bajos, 30 barcos de guerra y 4.000 soldados, en la ría de Burdeos, y sumas de dinero que ascendían a la ingente cantidad de 120.000 reales de a ocho mensuales, más otros 550.000, a pagar tras la firma del tratado ${ }^{143}$.

136. Ibid., doc. 32, Junta de Estado, 8-VIII-1651.

137. Ibid., doc. 50, Watteville a Felipe IV, 10-IX-1651 (llegada a San Sebastián de un enviado por Lusignan).

138. Tras su salida de prisión, había logrado cambiar el cargo de gobernador de la Borgoña por el de la Guyena.

139. AGS, Estado, leg. 2077, doc. 62, Junta de Estado, 27-IX-1651.

140. Ibid., doc. 77, Watteville a Felipe IV, 6-X-1651.

141. PUJO, Le Grand Condé..., p. 197.

142. AGS, Estado, leg. 2177, doc. 201, Tratado de Maubeuge, 26-X-1651.

143. «Tratado ajustado entre la Magestad Cathólica del señor D. Phelipe IV, de una parte, y el señor Luis de Borbón, Príncipe de Condé, el Príncipe de Conti y sus demás aliados, de otra». Figura en ABREU Y BERTODANO, Colección de los tratados..., pp. 110-137. La ayuda española se concretaba en: 500.000 patacones, en tres pagas, tras la firma del tratado; 
LOURDES AMIGO VÁZQUEZ

UN NUEVO ESCENARIO DE LA GUERRA CON FRANCIA.

LA INTERVENCIÓN ESPAÑOLA EN LA FRONDA (1648-1653)

Cumplida su misión, Lenet volvió rápidamente a Burdeos. En enero de 1652 ya estaba en Madrid Chauvigny Saint-Agoulin. Su estancia iba a ser también breve, como encargado de traer la ratificación de la alianza por parte de Condé y sus partidarios y volver a Burdeos con la de Felipe IV, a la vez que solicitar su puntual cumplimiento. Pero en junio volvió, ya como «son resident près de sa majesté catholique» ${ }^{144}$. De todas formas, el principal interlocutor de Saint-Agoulin no será el Príncipe, sino Lenet, en Burdeos. Además, muchos de los asuntos se trataron directamente por este último y Haro, a través de su rica correspondencia. En mayo de 1653, cuando la situación de Condé era ya insostenible, llegará a la corte española, para ocuparse de sus negocios, un noble titulado, el conde de Fiesque ${ }^{145}$.

Tanto Felipe IV como Haro constantemente insistieron al Príncipe y a sus representantes en el fiel cumplimiento del tratado. El 2 de mayo de 1652, su majestad escribía a Condé, dándole la enhorabuena de su victoria cerca de Châtillon, donde también habían participado los soldados del ejército de Flandes, concedidos al Príncipe. El rey terminaba la misiva de la siguiente forma:

Vous asseure qu'on ne perdra aucune occasion de vous assister, non seulement avec tout ce qui vous a esté offert, mais aussi avec tout ce qui sera de besoing; de quoy vous pouvez estre très certain, comme aussi de ce que je ne vous manquerey jamais pour aucune cause ${ }^{146}$.

Pero había una principal dificultad que pronto se hizo ostensible, la económica. El 15 de marzo de 1652, Haro ya tuvo que escribir a Lenet, poniendo como excusa la tardanza en la llegada de los galeones de América y asegurándole que «dès le primier (sic) iour qu’ils seront arrivez, monsieur le Prince será satisfaict iusques au

50.000 patacones al Príncipe de Conti, para su viaje a Provenza; 40.000 patacones mensuales, para el mantenimiento de las tropas; 120.000 patacones anuales, para los generales, oficiales, tren de víveres y artillería; Artillería, armas y municiones de guerra, a convenir con el barón de Watteville; 40.000 escudos mensuales, para el mantenimiento de las tropas, durante los 6 meses de campaña, y 20.000 escudos mensuales, el resto (tratado de Stenay); 60.000 patacones anuales, para gastos particulares del Príncipe (tratado de Stenay); 120.000 patacones anuales, para el mantenimiento de las plazas del Príncipe; 60.000 patacones anuales, para gastos de correos; 120.000 patacones anuales, para gastos extraordinarios; 120.000 patacones anuales, para gastos de príncipes, duques, etc.; 30 navíos de guerra, con gente de guerra y marina, y 4.000 infantes (para su guarnición debían entregar una puerto en la ría de Burdeos); 2.000 infantes y 3.000 caballos, armados (tratado de Stenay); 2.000 valones preparados, en Ostende, Nieuport o sus cercanías, para pasar por mar o tierra donde se ordenara.

144. AC, série P., vol. 12, fols. 254-257, Instrucción para Saint-Agoulin, 25-V-1652.

145. Sobre los representantes de Condé en la corte madrileña, vid. AMIGO VÁZQUEZ, L., «La otra imagen del héroe. El Grand Condé como aliado del rey de España (1651-1659)», Investigaciones Históricas. Época Moderna y Contemporánea, 38, 2018, pp. 187-218.

146. LENET, Mémoires..., p. 541.

Ediciones Universidad de Salamanca / @®@@ Stud. his., H. ${ }^{a}$ mod., 41, n. 1 (2019), pp. 153-188 
LOURDES AMIGO VÁZQUEZ

UN NUEVO ESCENARIO DE LA GUERRA CON FRANCIA.

LA INTERVENCIÓN ESPAÑOLA EN LA FRONDA (1648-1653)

dernier real de tout ce qui luy sera deu par le traicté» ${ }^{147}$. Además, la labor de coordinación y control de la ayuda, emprendida desde Madrid - y exigida por Condé y sus representantes -, será harto complicada, especialmente en el norte, al depender de los ministros de Flandes. Y, como veremos, tampoco faltarán los problemas en Burdeos, con Watteville.

Comencemos por el frente septentrional. En marzo de 1652, tras la firma de la alianza con el duque de Orleans, Condé abandona la Guyena y se dirige hacia el norte, tratando de ganar para su causa la capital, de donde la corte había salido. Allí se reúne con sus tropas que estaban en la frontera de los Países Bajos meridionales, unos 1.500 hombres, las del duque de Orleans y los 6.000 soldados dados por Fuensaldaña. El 11 de abril llega a París. Siguieron los combates, entre ellos el del faubourg de Saint Antoine, que hemos visto. Y si bien no faltaban los reproches del Príncipe a «les irresolutions des ministres de Flandre» desde la firma del tratado ${ }^{148}$, ahora definitivamente surgió el enfrentamiento, que se mantendrá durante sus años de exilio en aquellas provincias ${ }^{149}$. Uno y otros tuvieron conversaciones con la corte francesa, a espaldas de la otra parte; además, en opinión de Condé, pese a las órdenes de Madrid, desde Flandes no se le prestaba la ayuda necesaria, mientras que para sus autoridades se hacía cuanto se podía ${ }^{150}$. El 10 de agosto, Lenet se quejaba amargamente a Haro:

l'armée de monsieur le compte de Fuensaldagne est demeurée six semaines entières en mesme poste sans vouloir s'avancer ni se joindre avec son altesse quelque assurance qu'on luy en aye donnée; et dans le temps qu'elle croyoit s'aboucher avec ce général elle a sceu que luy et son armée se sont retirés sur leurs frontières, ayant laissé seulement quelques troupes sur la rivière d'Aisne et l'armée de monsieur de Loraine le soustient de ce parti ${ }^{151}$.

Fuensaldaña había entrado en Francia en julio, aunque no por mucho tiempo, debido, entre otras razones, a su falta de entendimiento con el Príncipe, por lo que "pareció no aventurarlo todo por socorrerle» ${ }^{152}$. Aun así, antes de retirarse hacia

147. Bibliothèque nationale de France, Département des manuscrits, Français 6731, fol. 102r, Haro a Lenet, 15-III-1652.

148. AGS, Estado, leg. 2079, doc. 32, Condé a Watteville, 1-I-1652.

149. Vid. AMIGO VÁZQUEZ, L.: «Instituciones y gobierno extraordinario. Flandes en tiempos del Grand Condé (1651-1659)», Philostrato. Revista de Historia y Arte, $\mathrm{n}^{\circ}$ extraordinario, marzo 2018, pp. 111-148.

150. AGS, Estado, leg. 2078, doc. 179, Fuensaldaña a Leopoldo-Guillermo, 18-VII-1652; Ibid., doc. 198, Junta de Estado, 31-VIII-1652; Ibid., doc. 224, Leopoldo-Guillermo a Felipe IV, 17-VIII-1652; AC, série P., vol. 12, f. 238-239, Fuensaldaña a Condé, 15-V-1655.

151. AC, série P, vol. 12, fol. 332r., Lenet a Haro, 10-VIII-1652.

152. AGS, Estado, leg. 2078, doc. 224, Leopoldo-Guillermo a Felipe IV, 17-VIII-1652; MAFFI, En defensa..., pp. 122-123. Hay que tener en cuenta que el duque de Lorena se encontraba por entonces exiliado en Flandes.

Ediciones Universidad de Salamanca / @®@@ Stud. his., H. ${ }^{a}$ mod., 41, n. 1 (2019), pp. 153-188 
Flandes, dejó «6.000 hombres de la gente de vuestra majestad y de la del partido incorporados con el duque de Lorena, a efecto de introducir el socorro al Príncipe, valiéndose de la mejor ocasión que se pudiere» ${ }^{153}$.

La situación de Condé en París acabó haciéndose insostenible. En agosto, Mazarin, sabedor que su presencia cerca de la reina constituía el principal obstáculo para la sumisión de la capital, salió hacia un segundo exilio. Finalmente, el 13 de octubre, el Príncipe se decide a huir, con su ejército, hacia la frontera norte. Aquí la historiografía tiende a dar por terminada la intervención personal de Condé en la Fronda, no incluyendo sus actividades militares posteriores. Se considera que comienza su exilio en Flandes y, con él, su servicio al rey de España. Pero todo esto no tendrá lugar hasta la caída de Burdeos, en el verano de $1653^{154}$. Es más, aún desde la distancia, seguirá dirigiendo el frente septentrional de las revueltas. Volvamos, pues, a este.

Watteville había llegado con la armada a la ría de Burdeos, en noviembre de 1651. Pero solo lo hacía con 20 navíos de guerra ${ }^{155}$. En enero de 1652, los españoles, tras un primer momento en Talmont, se establecieron definitivamente en Bourg, plaza que había que fortificar ${ }^{156}$. Se trató de incrementar el número de barcos, con 6 fragatas procedentes de Flandes, pero, por falta de dinero, sus autoridades no pudieron pagar ni su armazón ni su alquiler ${ }^{157}$. Al final, solo se lograron dos fragatas más. De todas formas, por cuenta de los 30 navíos ajustados en el tratado, la Monarquía Hispánica también se ocupará de mantener otros siete bajeles, 4 del Príncipe de Condé y 3 del conde du Dognon ${ }^{158}$. Tampoco se pudo alcanzar la cifra de los 4.000 soldados pactados. En septiembre de 1652, en la plaza de Bourg solo había, entre infantería española, irlandesa y alemana, 2.768 hombres, a los que se añadían otros 1.559, entre gente de mar y tierra, en los 13 navíos operativos entonces ${ }^{159}$. Nueve barcos se habían perdido, el 10 de agosto, en la que fue la gran operación militar española en el frente meridional. A fin de impedir que la flota real francesa atacase Burdeos, se decidió lanzar una ofensiva cerca de las costas de Bretaña, pero con escaso éxito,

153. AGS, Estado, leg. 2078, doc. 223, Leopoldo-Guillermo a Felipe IV, 10-VIII-1652.

154. AMIGO VÁZQUEZ, «Instituciones y gobierno...».

155. AGS, Estado, leg. 2079, doc. 123, Junta de Estado, 4-VIII-1653.

156. Ibid., doc. 31, Wateville a Felipe IV, 22-I-1652; LENET, Mémoires..., p. 536.

157. AGS, Estado, leg. 2077, doc. 104, Junta de Estado, 30-XII-1651; Ibid., leg. 2262, s.f., Felipe IV a Leopoldo-Guillermo, 28-V-1652; Ibid., leg. 2178, s.f., Fuensaldaña a Felipe IV, 16-VI-1652.

158. Ibid., leg. 2079, doc., Junta de Estado, 17-II-1652; Ibid., doc. 49, Junta de Estado, 11-III-1652; Ibid., doc. 52, Junta de Estado, 12-III-1652.

159. Ibid., doc. 192, Relación de la infantería que hay efectiva en la plaza de Bourg, 4-IX1652; Ibid., doc. 193, Relación de la gente de mar y tierra que hay en la armada desplazada a Burdeos, 6-IX-1652. 
ya que los navíos españoles fueron abandonados en la batalla por los del conde du Dognon, cuya marinería se amotinó ${ }^{160}$.

Tras la marcha de Condé hacia París, su hermano, el Príncipe de Conti y, sobre todo, Lenet, quedaron al frente de la situación en el sur. A medida que la guerra civil empeoraba para los frondistas también lo hacía la posición de Watteville. La causa principal era el dinero español, imprescindible, que llegaba a cuentagotas. Pero no solo eso. Como señalaba el barón a don Luis de Haro, el 5 de septiembre de 1652,

vuestra excelencia me perdone si le digo que hace quentas alegres quando se empeña con Saint Agoulin y escribe lo que se ha de dar a Lenet, sin saber lo que pasa aquí y que para esta armada y gente no se me ha embiado ni embía sino lo que saco de las partidas que bienen para el Príncipe ${ }^{161}$.

Las quejas de Watteville bien podrían estar fundadas, pero lo cierto es que desde Madrid se recriminó que de las cantidades que recibía, vía San Sebastián, entregara tan poco al partido ${ }^{162}$. Por ejemplo, el 24 de octubre, el barón informaba que de los 252.444 reales de a ocho que habían llegado con el navío la Gloria, solo 134.735 se habían dado al Príncipe ${ }^{163}$. Se dudó de su contabilidad y se envió a un comisario, Antonio Isasi, para ocuparse de la distribución del dinero ${ }^{164}$. Y la complicada relación que siempre había existido entre el barón y Lenet, estalló, por tal motivo, en noviembre de $1652^{165}$. Un enfrentamiento en el que este último logró el apoyo del Príncipe de Conti ${ }^{166}$ y llegó hasta el punto de solicitarse, a través de Saint-Agoulin, la sustitución de Watteville ${ }^{167}$. Madrid no pudo por menos que ordenar a su máximo representante en Burdeos que mantuviera «buena correspondencia con Lenet, mientras se ve claro que el Príncipe de Condé le tiene por su principal ministro y director de aquellas cosas» ${ }^{168}$.

En diciembre, los 13 navíos que quedaban de la armada volvían a Pasajes, para su carena, a fin de retornar lo antes posible ${ }^{169}$. Poco después, en enero, cuando la relación

160. Ibid., doc. 135, Watteville a Felipe IV, 12-VIII-1652; Ibid., doc. 191, Watteville a Felipe IV, 8-IX-1652.

161. Ibid., doc. 169, Watteville a Haro, 5-IX-1652.

162. Ibid., doc. 181, Junta de Estado, 29-IX-1652.

163. Ibid., doc. 228, Wateville a Felipe IV, 24-X-1652.

164. Ibid., doc. 242, Watteville a Felipe IV, 1-XII-1652 (informa de la llegada de este personaje).

165. Ibid., doc. 238, Watteville a Felipe IV, 7-IX-1652; Ibid., doc. 246, Watteville a Felipe IV, 5-XII-1652; Ibid., doc. 257, 12-XII-1652.

166. Real Academia de la Historia, Colección Salazar y Castro, A-100, f. 72, Conti a Watteville, 3-XII-1652.

167. LENET, Mémoires..., pp. 588-591 (Conti a Saint-Agoulin, 9-XII-1652).

168. AGS, leg. 2079, doc. 251, Junta de Estado, 30-XII-1652.

169. Ibid., doc. 258, Watteville a Felipe IV, 12-XII-1652. 
con Lenet estaba algo más calmada, también regresaba el barón de Watteville ${ }^{170}$. En teoría lo hacía para supervisar dicho apresto, si bien, según relataban, en mayo de 1653, a Condé sus hermanos, entonces enfrentados con Lenet, había sido para dar explicaciones en la corte de sus problemas con este ${ }^{171}$. En Bourg quedaban 2.336 hombres, bajo las órdenes de José de Vera Osorio.

Burdeos estaba prácticamente sitiada por tierra y por mar, en marzo de 1653. La situación era tan desesperada que sus autoridades enviaron a Madrid, primero a Chouppes y, después, de nuevo, al marqués de Lusignan ${ }^{172}$. También fue entonces cuando solicitaron ayuda a la Inglaterra de Cromwell ${ }^{173}$. El 5 de mayo, la Junta de Estado consideró necesario «acrecentar y apresusar las fuerças de mar». Asimismo, "para dar más crédito al negocio a los franceses que están aquí y a la misma villa de Burdeos», determinó encargar la empresa al marqués de Santa Cruz, general de la $\operatorname{armada} a^{174}$. Por su parte, Watteville también debería ir, aunque su marcha se fue retrasando y, al final, no se produjo ${ }^{175}$. El 28 de mayo ya se encontraba en Madrid el conde de Fiesque. Y, cómo no, el nuevo principal representante de Condé insistía en la urgente necesidad de socorrer Burdeos ${ }^{176}$.

El 18 de julio, la armada, con treinta navíos y al mando de Santa Cruz, logró salir a la mar. Pero era demasiado tarde. El 3 de julio, la plaza de Bourg, que estaba defendida por los españoles, se había rendido ${ }^{177}$. Además, Burdeos ya había entrado en negociaciones con Mazarin. En consecuencia, aunque el marqués de Santa Cruz llegó a la ría antes de la firma de la paz, que tuvo lugar el 27 de julio, no inició combate con la armada real francesa, por orden de Conti y Lenet ${ }^{178}$. El 2 de agosto, las tropas de Louis XIV entraban en la ciudad: la Fronda había terminado. El Príncipe de Conti y la duquesa de Longueville se acogieron al perdón real, mientras

170. Ibid., leg. 2082, doc. 2, Watteville a Felipe IV, 29-XII-1652; Ibid., Watteville a Felipe IV, 15-I-1653 (ya se encuentra en Pasajes).

171. AUMALE, Historie des princes..., vol. 6, p. 647 (Conti y duquesa de Longueville a Condé, 15-V-1653).

172. Sin contar con Lenet, el Príncipe de Conti mandó a Chouppes. Llegó a Madrid el 8 de marzo de 1653 y el 2 de abril ya se había embarcado en el puerto de Pasajes rumbo a Burdeos. A finales de abril debió de llegar Lusignan a Madrid. Su estancia también fue breve. Ya el 16 de mayo estaba en San Sebastián, con ánimo de embarcarse para Burdeos. Vid. AMIGO VÁZQUEZ, L.: «La otra imagen...».

173. GIRY-DELOISON, «Le rôle...», pp. 119-120.

174. AGS, Estado, leg. 2082, doc. 14, Junta de Estado, 5-V-1653.

175. Ibid., doc. 15, Junta de Estado, 21-V-1653 (partiría lo antes posible con Lusignan, llevando el dinero); Ibid., doc. 20, 30-V-1653 (Lusignan partiría con el dinero, con Santa Cruz, y posteriormente lo haría Watteville con Fiesque).

176. Ibid., Estado K, leg. 1405, doc. 22, Memoria de Fiesque a Haro, 29-V-1653.

177. Ibid., Estado, leg. 2082, doc. 22, Watteville a Felipe IV, 19-VII-1653.

178. Ibid., doc. 24, Junta de Estado, 23-VIII-1653. 
que su esposa y otros leales seguidores del Grand Condé se marcharon al exilio en Flandes. Precisamente, fue un navío español el que trasladó a la Princesa ${ }^{179}$. De todas formas, con el visto bueno de los ministros de Condé, Santa Cruz atacó a la armada francesa, el 20 de octubre. Aunque en un principio tuvo éxito, no logró la conquista de la isla de Ré, razón por la que se volvió a España ${ }^{180}$.

El 30 de julio de 1653, Conti escribía a su hermano, señalándole que se había visto obligado a firmar la paz, debido, entre otras razones, a la «trahison des Espagnols» ${ }^{181}$. Felipe IV no había cumplido con lo pactado. Sin embargo, la corte madrileña consideraba que el principal error había sido de Condé, por haber abandonado la Guyena, donde residía su principal apoyo y era más fácil hacerle llegar la ayuda, y centrar sus objetivos en París y en el norte. Una opinión que ya la Junta de Estado había planteado en noviembre de 1652, tras su huida de la capital francesa, y volvía a recordar en septiembre del año siguiente ${ }^{182}$. Además, desde Flandes, con el visto bueno de Madrid, se había propuesto al Príncipe volver a Burdeos, antes de su caída, para ponerse al frente de la rebelión, pero no había querido ${ }^{183}$.

\section{A MODO DE CONCLUSIÓN}

Como señalaba a Haro el propio barón de Watteville, el 7 de noviembre de 1652, «es imposible que su majestad cumpla con todo lo prometido en el tratado» ${ }^{184}$. Las cantidades de dinero pactadas no eran asumibles para una Monarquía con tantos frentes de guerra abiertos y una muy difícil situación financiera. De todas formas, con sus limitaciones, la intervención en la Fronda de Condé, así como en los episodios anteriores, logró, en líneas generales, el fin que se había planteado desde sus inicios: fomentar las guerras intestinas en Francia y sacar beneficio con ello. Aunque, ciertamente, no tanto como el deseado, que era obligar a la Corona francesa a la firma de la paz, debido a que falló la ayuda española, pero, sobre todo, a la propia debilidad interna de las revueltas frente al poder real.

179. Ibid., doc. 27, Watteville a Felipe IV, 19-VIII-1653.

180. Relación verdadera de la famosa vitoria que ha tenido el excelentísimo señor don Álbaro Baçan, marqués de Santa Cruz, general de la armada real de España, que está sobre la ría de la ciudad de Burdeos, sucedida a 20 de octubre de 1653. Sevilla, 1653; AGS, Estado, 2264, s.f., Felipe IV a Leopoldo-Guillermo, 13-XI-1653.

181. AUMALE, Histoire des princes..., vol. 6, p. 661 (Conti a Condé, 30-VII-1653).

182. AGS, Estado, leg. 2078, doc. 254, Junta de Estado, 8-XI-1652; Ibid., leg. 2080, doc. 75, Junta de Estado, 28-IX-1653.

183. Ibid., leg. 2081, doc. 132, Fuensaldaña a Felipe IV, 16-V-1653; Ibid., doc. 129, Consejo de Estado, 11-VII-1653; Ibid., leg. 2083, doc. 81, Consejo de Estado, 5-VII-1653.

184. Ibid., leg. 2079, doc. 238, Watteville a Felipe IV, 7-XI-1652. 
LOURDES AMIGO VÁZQUEZ

UN NUEVO ESCENARIO DE LA GUERRA CON FRANCIA.

LA INTERVENCIÓN ESPAÑOLA EN LA FRONDA (1648-1653)

La Fronda, no en poca medida alimentada por la Monarquía Hispánica, hasta el punto que sin su implicación el alcance de los disturbios hubiera sido mucho más limitado, fue uno de los factores que contribuyó a que esta experimentara, entre 1647 y 1656, una fase de recuperación en la Guerra Franco-Española y a que 1652 pudiera considerarse un verdadero «annus mirabilis» ${ }^{185}$. Un hecho que no pasó desapercibido para los propios frondistas. Tras la rendición de Barcelona, contaba Watteville que en Burdeos se pedía todavía con mayor vehemencia el dinero que se les había prometido, «lamentándose con injustas exclamaciones y como arrepentidos de parecelles de aver sido causa de los buenos sucesos que an tenido en esta campaña las armas de vuestra majestad, en todas partes» ${ }^{186}$. Otra cuestión sería si a largo plazo esta intervención fue o no positiva, ya que a Felipe IV le quedó como herencia su difícil alianza con el Grand Condé, exiliado en los Países Bajos meridionales hasta la firma del Tratado de los Pirineos, en $1659^{187}$.

\section{BIBLIOGRAFÍA}

ABREU Y BERTODANO, J. A. de: Colección de los tratados de paz [...]. Reinado de Phelipe IV. Parte IV. Madrid, Antonio Marín, Juan de Zúñiga y la viuda de Peralta, 1751.

AMIGO VÁZQUEZ, L.: «Instituciones y gobierno extraordinario. Flandes en tiempos del Grand Condé (1651-1659)», Philostrato. Revista de Historia y Arte, $\mathrm{n}^{\circ}$ extraordinario, marzo 2018, pp. 111-148.

AMIGO VÁZQUEZ, L., «La otra imagen del héroe. El Grand Condé como aliado del rey de España (1651-1659)», Investigaciones Históricas. Época Moderna y Contemporánea, 38, 2018, pp. 187-218.

Archives historiques du département de la Gironde. París y Burdeos, Chez Aug. Aubry, Librarie y Chez E.-G. Gounouilhou, 1861-1862 y 1863, vols. 3 y 4.

ARLETTE, J.: Le devoir de révolte. La noblesse française et la gestation de l'État moderne, 1559-1661. París, Fayard, 1989.

AUMALE, H. d'Orleans, duque de: Histoire des princes de Condé anx XVe et XVIIe siècles. París, Calmann Lévy, éditeur, 1892, 1896, vols. 6 y 7.

BÉGUIN, K.: Les princes de Condé. Rebelles, courtisans et mécènes dans la France du Grand Siècle. Seyssel, Champ Vallon, 1999.

BENAVIDES, J. I., Milicia y diplomacia en el reinado de Felipe IV. El marqués de Caracena. Astorga, Akrón, 2012.

185. MAFFI, En defensa..., pp. 126 y $140-141$.

186. AGS, Estado, leg. 2079, doc. 240, Watteville a Felipe IV, 24-XI-1652.

187. Vid. INGLISH-JONES, J.J.: The Grand Condé in exile: Power Politics in France, Spain and the Spanish Netherlands. 1652-1659. Tesis Doctoral inédita, Universidad de Oxford, 1994; AMIGO VÁZQUEZ, «Instituciones y gobierno...» y «La otra imagen...».

Ediciones Universidad de Salamanca / అ@@ Stud. his., H. ${ }^{a}$ mod., 41, n. 1 (2019), pp. 153-188 
LOURDES AMIGO VÁZQUEZ

UN NUEVO ESCENARIO DE LA GUERRA CON FRANCIA.

LA INTERVENCIÓN ESPAÑOLA EN LA FRONDA (1648-1653)

BERCÉ, Y.-M.: Histoire des croquants, étude des soulèvements populaires au XVIIe siècle dans le Sud-Onest de la France. Ginebra, Droz, 1974, 2 vols.

BERCÉ, Y.-M.: «Le rôle des Suisses pendant la Fronde: maîtres ou serviteurs?», Cinq siècles de relations franco-suisses. Neuchâtel, Editions de la Baconnière, 1984, pp. 73-87.

BÉRENGER, J.: Turenne. París, Fayard, 1987.

BERTIÈRE, S.: Condé, le héros fourvoyé. París, Éditions de Fallois, 2011.

BIRNSTIEL, E.: Die Fronde in Bordeaux, 1648-1654. Francfort-sur-le-Main, Verlag Peter Lang, 1985.

BLANQUIE, C.: Une vie de frondeur, le chevalier de Thodias (1616-1672). Coutras, Groupe de Recherches Archéologiques et Historiques de Coutras, 2001.

BORREGO, M.: «España en las mazarinadas (1648-1652), una aproximación», en GARCÍA LÓPEZ, J. y BOADAS, S. (eds.): Las relaciones de sucesos en los cambios politicos y sociales de la Europa Moderna. Bellaterra, Universitat Autònoma de Barcelona, 2015.

CONSTANT, J.-M.: Les conjurateurs: le premier libéralisme politique sous Richelieu. París, Hachette, 1986.

CONSTANT, J.M.: C'était la Fronde. París, Flammarion, 2016.

COUSIN, V.: Madame de Chevreuse. París, Didier, 1862 (2ª ed.).

COUSIN, V.: Madame de Longueville pendant la Fronde, París, Didier, 1881 (6 $\left.6^{\mathrm{a}} \mathrm{ed}.\right)$.

DAST DE BOISVILLE, M.: "La Fronde en Guyenne», en Autographes de Personnages Ayant Marqué Dans L'bistoire de Bordeaux et de la Guyenne. Burdeos, Imprimerie G. Gounouilhou, 1895.

DUCHÊNE, R. y RONZEAUD, P. (dirs.): La Fronde en questions. Aix-en-Provence, Universtié de Provence, 1989.

ESTEBAN ESTRÍNGANA, A.: Madrid y Bruselas. Relaciones de gobierno en la etapa postarchiducal (1621-1634). Leuven, Leuven University Press, 2005.

GIRY-DELOISON, C.: «Le rôle de l'Anglaterre dans les événements de la Fronde bordelaise 1649-1653», en COCULA, A.-M. (ed.): Adhésion et résistences à l'État en France et en Espagne 1620-1660. Pessac, Presses Universitaires de Bordeaux, 2001, pp. 111-135.

GUTTON, J.-P.: Dévots et société au XVIIe siècle. París, Belin, 2004.

INGLISH-JONES, J. J.: The Grand Condé in exile: Power Politics in France, Spain and the Spanish Netherlands. 1652-1659. Tesis Doctoral inédita, Universidad de Oxford, 1994.

JOUHAUD, C.: «Geoffroy Gay: une lecture de la Fronde Bordelaise», Annales du Midi, 91, no 143, 1979, pp. 273-295.

KNACHEL, P. A.: England and the Fronde. The Impact of the English Civil War and Revolution on France. Ithaca, New York, Cornell University Press, 1967.

KOSSMANN, E. H.: La Fronde. Leyde, Universitaire Pers Leiden, 1954.

KOTTING, H.: Die Ormée, 1651-1653. Münster, Aschendorff, 1983.

LE MAO, C.: Parlement et Parlementaires. Bordeaux au Grand Siècle. Seyssel, Champ Vallon, 2007.

LENET, P.: Mémoires. París, Chez l'éditeur du commentaire analytique du code civil, 1838 (ed. Michaud y Poujoulat).

Ediciones Universidad de Salamanca / @®@@ Stud. his., H. ${ }^{a}$ mod., 41, n. 1 (2019), pp. 153-188 
LOURDES AMIGO VÁZQUEZ

UN NUEVO ESCENARIO DE LA GUERRA CON FRANCIA.

LA INTERVENCIÓN ESPAÑOLA EN LA FRONDA (1648-1653)

LONCHAY, H. et al. (ed.): Correspondance de la cour d'Espagne sur les affaires des PaysBas au XVIIe siècle. Bruselas, Maurice Lamertin, 1933, vol. 4.

MAFFI, D.: En defensa del Imperio. Los ejércitos de Felipe IV y la guerra por la hegemonía europea (1635-1659). Madrid, Editorial Actas, 2014.

MALCOLM, A.: Royal Favouritism and the Governing Elite of the Spanish Monarchy 1640-1665. Oxford, Oxford University, 2017.

MÉTHIVIER, H.: La Fronde. París, Presses Universitaires de France, 1984.

MOOTE, A. L.: The Revolt of the judges: the Parlement of Paris and the Fronde, 16431652. Princeton, Princeton University, 1971.

PERNOT, M.: «Le rôle politique du cardinal de Retz pendant la Fronde», XVIIe Siècle, 192, 1996, pp. 623-632.

PERNOT, M.: La Fronde. 1648-1653. París, Éditions du Fallois, 1994.

POISSON, G.: La duchesse de Chevreuse. París, Perrin, 1999.

PUJO, B.: Le Grand Condé. París, Albin Michel, 1995.

RANUM, O. A.: La Fronde. París, Éd. du Seuil, 1995.

Relación verdadera de la famosa vitoria que ha tenido el excelentísimo señor don Álbaro Baçan, marqués de Santa Cruz, general de la armada real de España, que está sobre la ría de la ciudad de Burdeos, sucedida a 20 de octubre de 1653. Sevilla, Juan Gómez de Blas, 1653.

RETZ, Cardenal de: Mémoires. París, Le Livre de Poche, 2010 (ed. S. Bertière).

RUIZ IBÁÑEZ, J. J.: Laberintos de hegemonía. La presencia militar de la Monarquía Hispánica en Francia a finales del siglo XVI. Valladolid, Universidad de Valladolid, 2012.

SÁNCHEZ MARTÍN, J. L.: «Wattevile de Joux, Carlos», en Diccionario Biográfico Español [http://dbe.rah.es/biografias/49423/carlos-watteville-de-joux].

SÉRÉ, D.: La Paix des Pyrénées. Vingt-quatre ans de négociations entre la France et l'Espagne (1635-1659). París, H. Champion, 2007.

SERPELL, D.R.: The condicion of Protestantism in France and its influence on the relations of France and England 1650-1654. Toulouse y París, Privat y Didier, 1934.

SERVANTON, M.: Factions et robes rouges: parlements et politique provinciale de Richelien à la Fronde (1624-1654), tesis doctoral inédita, Université Bourdeaux Montaigne, 2017.

SONNINO, P.: Mazarin's Quest: The Congress of Westphalia and the Coming of the Fronde. Cambridge y Londres, Harvard University Press, 2008.

THIÉRY, H.: «À la découverte d'un acteur de la Fronde à Bordeaux: la mission du baron de Vatteville (1649-1653)», Annales du Midi, 265, 2009, pp. 37-56.

TRIBOUT, B.: «Retz et Mazarin: polémique et politique dans les 'Mémoires' de Retz», Studi Francesi, 170 (57, 2), 2013, pp. 235-245.

USUNÁRIZ GARAYOA, J.: «'Las grandes novedades que ha habido en el reino de Francia'. La Fronda vista desde España», en RONCERO LÓPEZ, V. y ESCUDERO BAZÁN, J. M. (eds.): "Doctos libros juntos». Homenaje al profesor Ignacio Arellano Ayuso. Madrid, Iberoamericana, 2018, pp. 493-508.

VALLADARES, R. (ed.): El mundo de un valido. Don Luis de Haro y su entorno, 16431661. Madrid, Marcial Pons, 2016.

Ediciones Universidad de Salamanca / అ@@ Stud. his., H. ${ }^{a}$ mod., 41, n. 1 (2019), pp. 153-188 
VÁZQUEZ DE PRADA, V.: Felipe II y Francia (1559-1598). Política, Religión y Razón de Estado. Pamplona, Eunsa, 2004.

VERGNES, S.: Les frondeuses. Une révolte au féminin (1643-1661). Seyssel, Champ Vallon, 2013.

VERMEIR, R.: «Un austriaco en Flandes. El archiduque Leopoldo Guillermo, Gobernador General de los Países Bajos meridionales (1647-1656)», en MARTÍNEZ MILLAN, J. y GONZÁLEZ CUERVA, R. (coords.): La dinastía de los Austria: las relaciones entre la Monarquía Católica y el Imperio. Madrid, Polifemo, 2011, vol. 1.

VINCART, J. A.: Relación de los sucesos de las armas de su majestad católica (...) de la campaña y año de 1649, en Biblioteca Nacional de España, mss. 3132.

WESTRICH, S. A.: The Ormée of Bordeaux: a revolution during the Fronde. Baltimore, The Johns Hopkins University, 1972.

XVIIe siècle, 145, no 4, 1984 (número monográfico sobre la Fronda).

Ediciones Universidad de Salamanca / @®@@ Stud. his., H. ${ }^{a}$ mod., 41, n. 1 (2019), pp. 153-188 